\title{
Ambitious Mashups: Reflections on a Decade of Cyberlearning Research
}

by the Center for Innovative Research in Cyberlearning September 2020

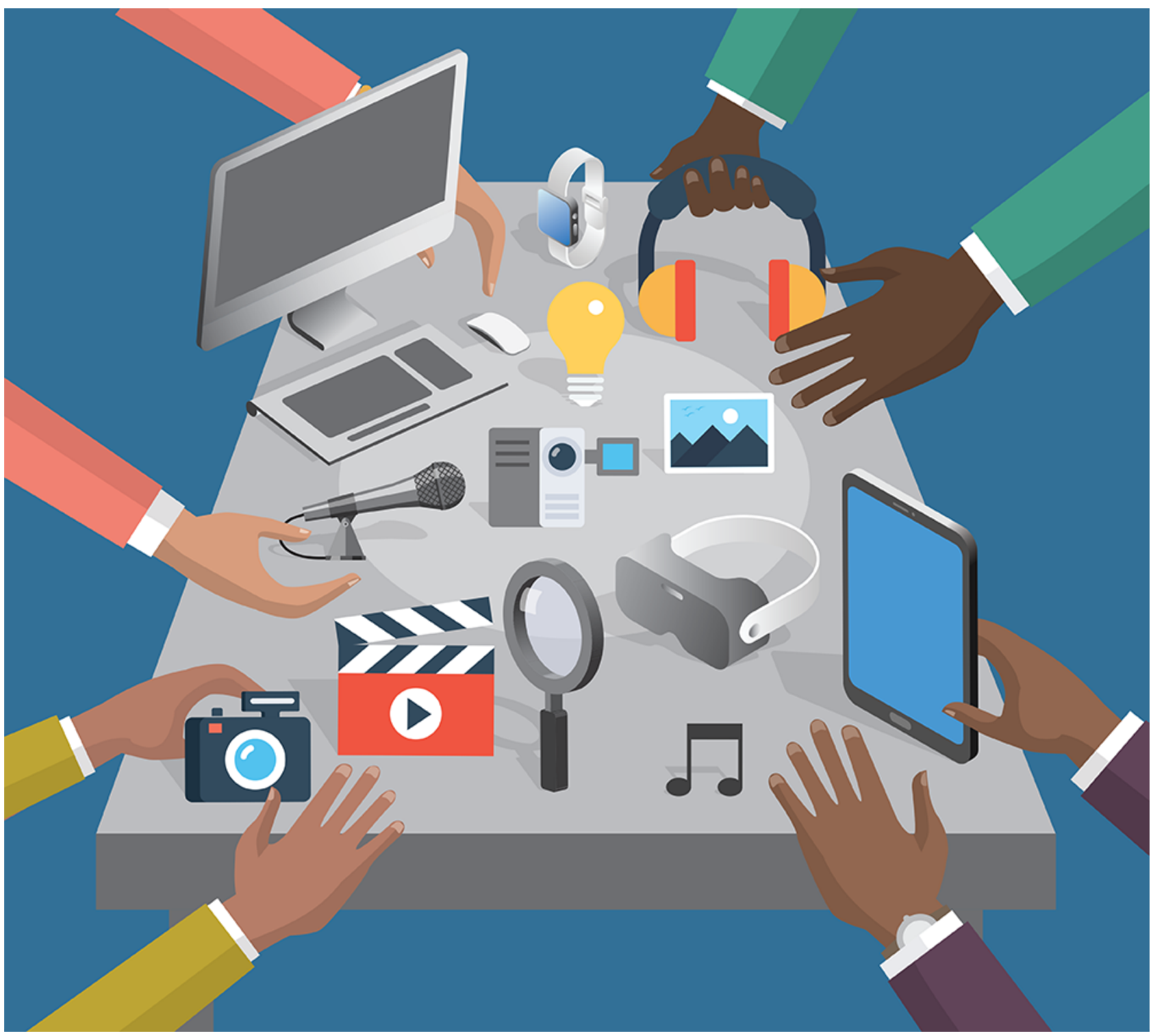

\section{CIRCL}

Center for Innovative

Research in Cyberlearning

Digital Promise
SRI Education

NERC

at the UNIVERSITY of CHICAGO 


\section{Suggested Citation}

Center for Innovative Research in Cyberlearning (2020). Ambitious mashups: Reflections on a decade of cyberlearning research. [Report]. Digital Promise.

https://circlcenter.org/resources/reflections-report/.

Roschelle, J. \& Schank, P. (2020) Artificial intelligence \& learning. In Center for Innovative Research in Cyberlearning, Ambitious mashups: Reflections on a decade of cyberlearning research. (pp. 8-10). Digital Promise.

Fusco, J. \& Roschelle, J. (2020) Learning theories. In Center for Innovative Research in Cyberlearning, Ambitious mashups: Reflections on a decade of cyberlearning research. (pp. 11-14). Digital Promise.

Fusco, J. \& Schank, P. (2020) Research methods. In Center for Innovative Research in Cyberlearning, Ambitious mashups: Reflections on a decade of cyberlearning research. (pp. 15-18). Digital Promise.

Martin, W. (2020) Out-of-school-time (OST) learning. In Center for Innovative Research in Cyberlearning, Ambitious mashups: Reflections on a decade of cyberlearning research. (pp. 19-22). Digital Promise.

Pillai, S. (2020) Trends at NSF and beyond. In Center for Innovative Research in Cyberlearning, Ambitious mashups: Reflections on a decade of cyberlearning research. (pp. 23-26). Digital Promise.

\section{Acknowledgements}

We thank our expert panelists for contributing to the reflections process: Guy- Alain Ammoussou, Peter Brusilovsky, John Cherniavsky, Danny Edelson, Chris Hoadley, Sherry Hsi, Ken Koedinger, Janet Kolodner, Stephanie Teasley and Erin Walker. Thanks also to our program officers, Amy Baylor and Tanya Korelsky.

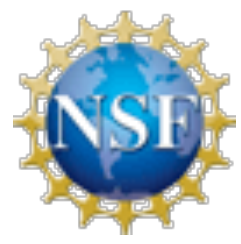

This material is based upon work supported by the National Science Foundation under grants 1837463 and 1233722 . Any opinions, findings, and conclusions or recommendations expressed in this material are those of the author(s) and do not necessarily reflect the views of the National Science Foundation. 


\section{Table of Contents}

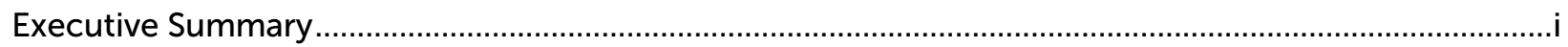

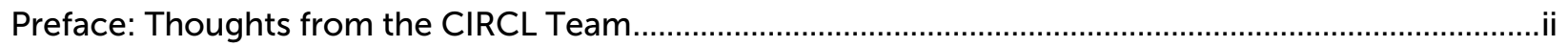

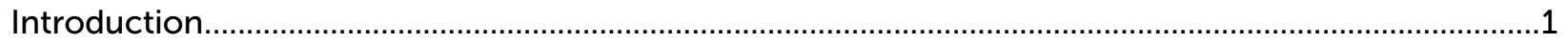

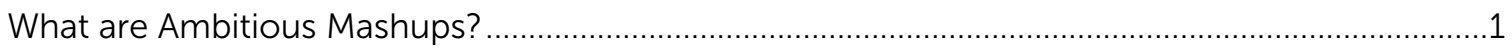

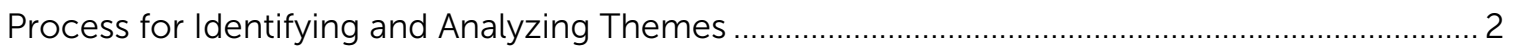

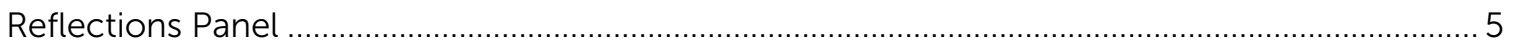

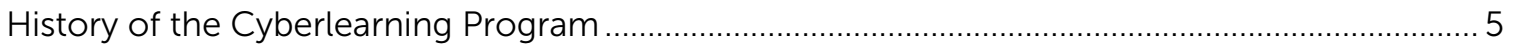

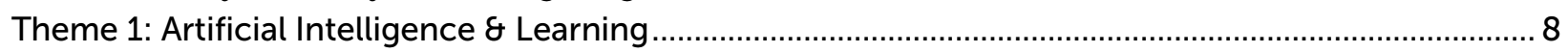

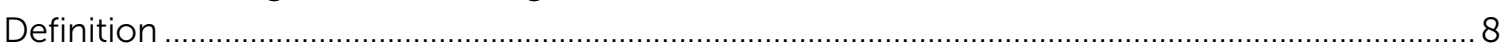

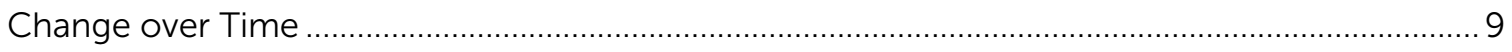

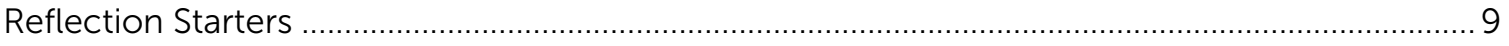

Recommendations from the Reflections Panel ............................................................................... 10

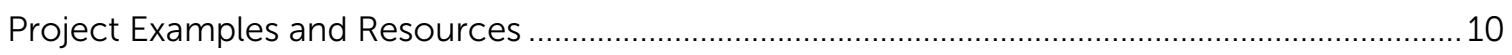

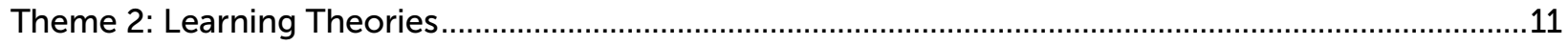

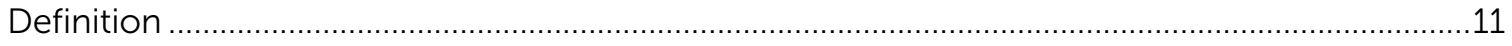

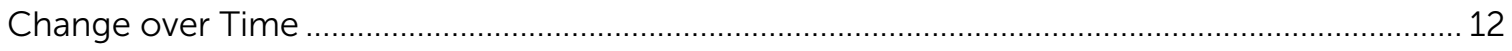

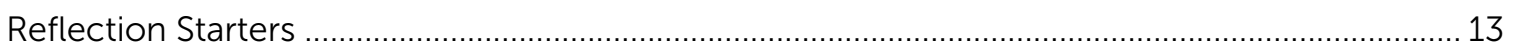

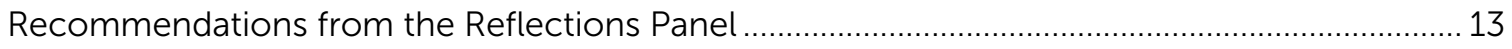

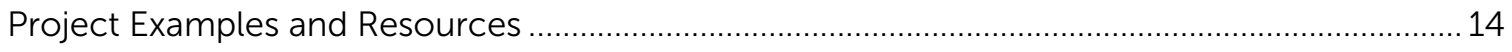

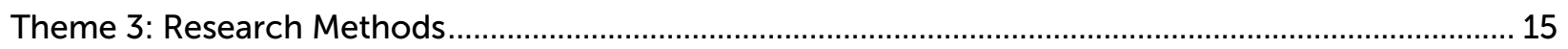

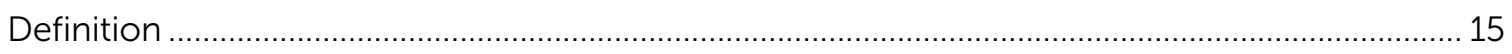

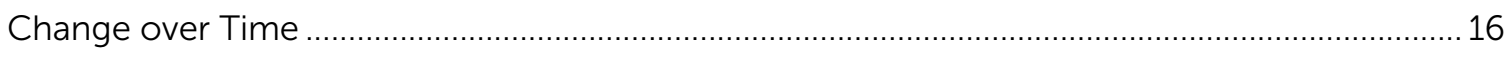

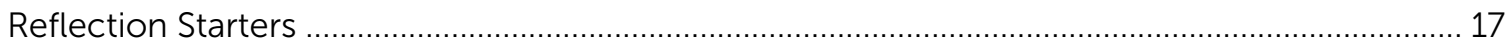

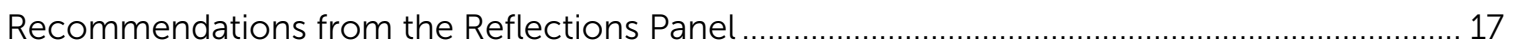

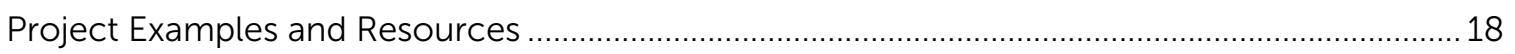

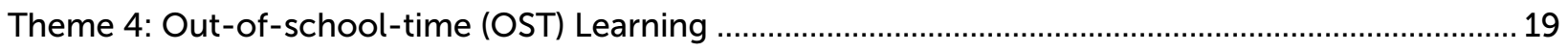

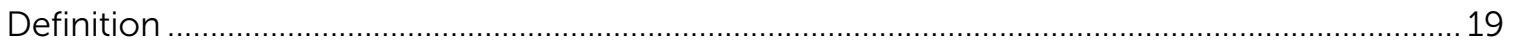

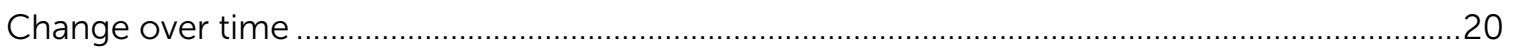

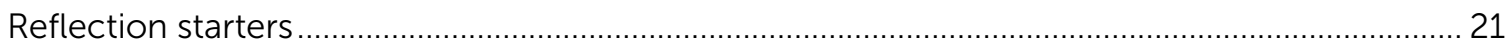

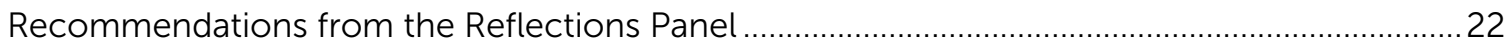

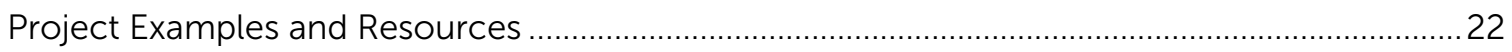

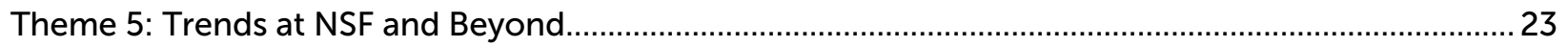

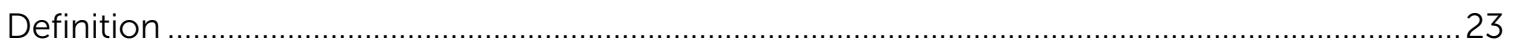

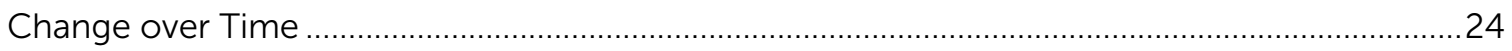

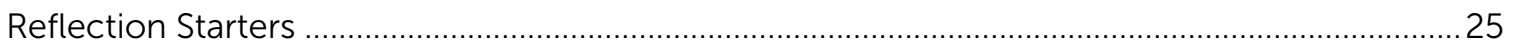

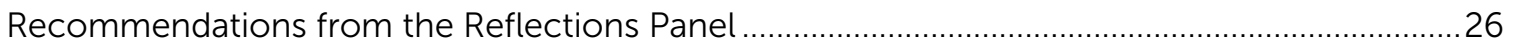

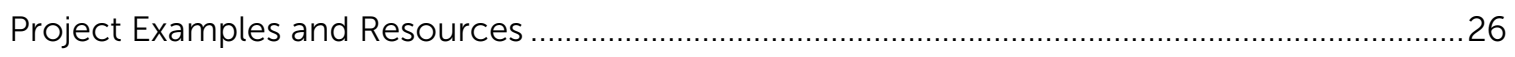

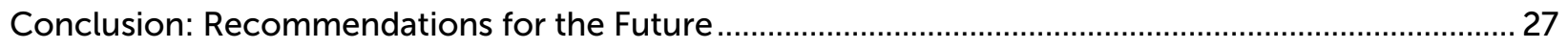

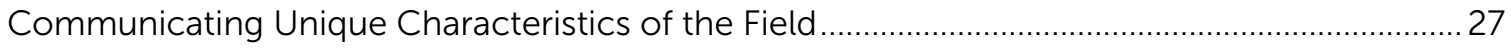

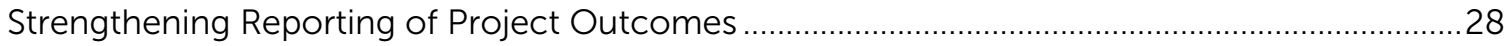

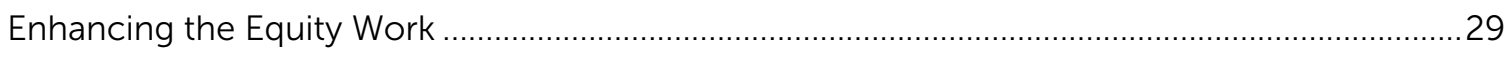

Appendix 1: Findings from the 2020 Project Exit Survey .................................................................... 30 


\section{Executive Summary}

This report reflects on progress from over eight years of research projects in the cyberlearning community. The community involved computer scientists and learning scientists who received NSF awards to investigate the design of more equitable learning experiences with emerging technology-focusing on developing the learning theories and technologies that are likely to become important within 5-10 years. In early 2020, our center's team analyzed the portfolio of past and current projects in this community, and convened a panel of experts to reflect on important trends and issues.

The concept of "ambitious mashups" arose during this review. We observed that cyberlearning projects combine many elements in novel integrations, leading to the design and study of promising approaches to a range of learning goals - these projects are not about only one type of technology. The projects are also unmistakably ambitious. We observed that projects push toward frontiers of knowledge, seek to advance design, theory, methods and applications simultaneously, and tackle big learning goals and not just incremental improvements to the status quo. Cyberlearning projects design ambitious mashups and they investigate what happens when learners inhabit the designs.

Our review found five themes that account for the most dynamic elements of the cyberlearning community: incorporation of Al in learning, advances in learning theories, expansion of research methods, incorporation of out-of-school learning, and the alignment of scientific policy development to NSF projects and beyond. For each of these themes, the report elaborates the nature of each area, describes how the community changed over time, shares reflective questions that arose through our review, and shares recommendations from our expert panel.

We conclude with three overarching recommendations from the panel. First, this field of research should communicate more clearly about the unique characteristics of its researchto distinguish this dynamic (yet relatively small) body of work from more general waves of educational technology R\&D. Communicating clearly can encourage proposals and awards that offer distinctive value and sharpen the contributions this work can make to society. Second, the field needs to strengthen reporting of project outcomes. At the moment, it is too hard to learn what is being accomplished. Third, the field should continue to sharpen and advance the equity work within its thematic research.

An online companion to this report offers resources to enable readers to explore cyberlearning research more deeply and is available at:

https://circlcenter.org/resources/reflections-report/. 


\title{
Preface: Thoughts from the CIRCL Team
}

\author{
"Yesterday is gone. Tomorrow has not yet come. \\ We have only today. Let us begin." \\ - Mother Teresa
}

For eight years, our team at the Center for Innovative Research in Cyberlearning has had the privilege of working with a dynamic community of researchers who were awarded grants by the National Science Foundation in the area of cyberlearning. We've been inspired by the depth of concern in the community for issues of equity as technology advances to shape learning in more and more contexts.

This community, we've learned, definitely does not dwell on historical technologies for learning or even those that are commonplace today. Technology for learning is changing rapidly, and by the time today's research could do something to improve older technologies-for example, those typically found today's online courses-these technologies will be a "yesterday" that is gone.

The community is oriented to exploring future learning that leverages newly emerging technologies - technologies that are not yet here in terms of broad acceptance, but which likely will become important to large numbers of future learners. Advances in speech, gesture, and vision are examples that may be leveraged in future learning tools, but still aren't commonplace in today's educational technology.

What learning theories will we need to use these capabilities well? What new equity challenges will emerge and how can we tackle them? How can we work now towards a better future of learning, 5-10 years from now?

To answer these questions, researchers in the cyberlearning program bring together three components: computer science expertise, learning sciences theories and methods, and a commitment to investigating equity. The core challenge of the research is to figure how we can begin today to study and improve a tomorrow which has not yet come. Projects involve designing prototypes that anticipate possible futures and studying them, especially with an eye to uncovering the issues and strengthening the theories needed to address those issues. We at CIRCL have had the role of organizing a community of such projects, sharing knowledge across boundaries, and seeking synergies among the individual projects.

In March 2020, along with many colleagues, we found ourselves working in new situations due to the coronavirus pandemic. Also, we knew that the funding cycle for CIRCL would come to an end soon, in September 2020. We decided to make use of the disruption in our routines as well as the pressure of time to reflect deeply on how the portfolio of projects in this community evolved over eight years. We worked together to analyze the considerable archives we had of past projects, reports, convenings, and themes. And we invited external experts to join a virtual meeting to reflect with us. These experts included all the past NSF program officers involved in cyberlearning as well as many of CIRCL's advisors over the years.

In our reflections, we realized how the emphasis on the researchers in the portfolios evolved. The program didn't proceed as its designers first imagined-well, not exactly, anyway. But it did proceed in ways that appear to make it more relevant and important for the future. One important example is that the program originally aimed to explore "genres" of future learning 
technology, a term that eluded clear definition. Through our reflective examination of the archives, we observed that the program instead appeared to emphasize "ambitious mashups"-projects in which a set of novel technologies were brought together in unimagined ways to tackle a learning challenge-with researchers studying how learning proceeds in that mashup. By exploring a particular ambitious mashup, researchers aimed to gain design insights, to elaborate learning theories, and to refine research methods to work better with future technologies.

We anticipate that more research like this will occur in the future. Our society faces a tension between the fast pace of change in technology for learning and the slow pace of developing research-based understanding of how to equitably use those technologies. Hence, we take this pause to reflect on the character of "research like this" and to seek recommendations for how the community can do it better in the future. What can we do better with our "today?"

Although as researchers we operate in a different space than Mother Teresa, her quote resonates with us as researchers and challenges us to work now for more equitable educational futures. We recognize that technology is a huge part of how learning happens now (especially with remote learning in this pandemic era) and it's likely to be an even bigger and stranger part of how learning happens in the future. We recognize that the incessant arrow of time may produce learning technologies that disadvantage some students or that make today's inequities worse. We need to urgently anticipate the issues and conduct research to address them. We can't think of any other community of similarly funded researchers exploring future learning theories, emerging technologies, and equity challenges with the intensity of this research community. So, it is up to this cyberlearning community to do this work now, before the future arrives. We have today. Let's begin.

\section{The CIRCL Team}

Jeremy Roschelle, PI

Sarita Pillai, co-PI

Patricia Schank, co-PI

Kevin Brown

Carly Chillmon

Judi Fusco

Shari Gardner

Wendy Martin

Jonathan Pittman

Pati Ruiz 


\section{Introduction}

This report reflects on the progress from over eight years of research projects in the cyberlearning community. The projects in this NSF-funded portfolio each involved computer scientists and learning scientists working together with a focus on exploring the future to support design of more equitable learning experiences with technology. Over the past 6 months we analyzed the portfolio of past and current projects, and met with expert advisors to consider important trends and issues. We begin this report by discussing a shared characteristic of many of the projects that became apparent to us as we examined the portfolio-and which resonated with the panelists who met with us to reflect on the portfolio.

\section{What are Ambitious Mashups?}

The concept of "ambitious mashups" describes what makes this collection of projects special and worthy of review. We first tried to categorize or tag the projects, but soon realized that many projects defied simple characterization. Projects did not fall into one major technology that they were exploring. Nor did they only refine one research method. Nor did they develop only one type of learning theory. The interdisciplinarity of the projects created new combinations of methods to address problems. Equity concerns that arose were also not singular.

The projects we reviewed were mashups - they combined many elements in a novel integration, to explore a promising approach to a particular learning goal or context. A project, for example, might involve elements of artificial intelligence, virtual reality, and dynamic simulations. It might involve theories of collaborative learning, learning from representations and embodied learning. Methods could involve analyzing discourse, embodied cognition, and learning analytics.

The projects also were very ambitious. These were not integrations of the most established aspects of each technology, theory, or method. Rather they were pushing for frontierstrying to explore combinations which do not easily co-occur with today's learning environments, but might co-occur in the future. Projects were also ambitious in terms of wanting to study big learning goals; they did not focus on incremental improvements in test scores. Rather they were working to open up difficult subjects so that more students could learn them and/or challenging who can learn important scientific topics in ways that feel personally relevant and connected.

Cyberlearning projects design ambitious mashups and they investigate what happens when learners inhabit them. The output isn't usually intended to be a "solution" that "scales up"that would be a near-term goal to apply technology to learning. Rather the output is usually intended to reach a better understanding of a technology, a theory, a method, or an approach to equity-an understanding that might be applied more broadly in the future as it arrives. Indeed, cyberlearning projects also have a strong focus on groups that are underrepresented in STEM professions, with projects often stating a specific focus on underrepresented minorities, women/girls, low-performing schools, low-income settings, students with a disability, or students who are learning English.

The report that follows explores the intents and outputs of cyberlearning projects in more detail. 


\section{About the Cyberlearning Community}

Our center, CIRCL, nurtured a community among the investigators of separately funded NSF projects that either were directly funded by one of the cyberlearning programs at NSF or were tagged by NSF program officers as cyberlearning-relevant. About 450 projects and two thousand investigators participated in at least one $C I R C L$ event. A recent exit survey of cyberlearning projects found that almost all projects include both a computer scientist and a learning scientist. A more detailed look reveals that:

- Prominent education or learning disciplines include Curriculum and Instruction, Cognitive Psychology (or Cognitive Science), Informal Education, and Special Education.

- Prominent computer science areas include Artificial Intelligence, Machine Learning, Learning Analytics, Artificial and Virtual Reality, Natural Language Processing, and Biometrics

- Projects often also have expertise in a STEM disciplines such as Life Sciences, Engineering, Mathematics, and Digital Media (or Communication).

- Other cited disciplines include Social Science, Business, Humanities, Graphic Design

- Teachers are partners in $58 \%$ of projects

- Almost all projects train at least one graduate student, usually with multidisciplinary focus

Despite the overall underrepresentation of women in Computer Science, cyberlearning projects have more women than men as computer science Pls of projects in recent years.

Projects take place in a mix of settings, with strong representation of both formal and informal education settings, as well as a small but growing number of projects in workplaces. Across the portfolio, projects work with learners of all ages. Individual projects may be explored via the interactive Project Tag Map.

\section{Process for Identifying and Analyzing Themes}

Our team chose and analyzed key themes for the Reflections Briefs and expert panel meeting using a hybrid approach of bottom-up (data driven) and top-down (knowledge driven) methods.

The bottom-up approach leveraged tags derived from the cyberlearning portfolio. All NSFfunded cyberlearning projects on the CIRCL website are tagged by one or more of roughly 50 tags (see Figures 1 and 2). These tags were generated by the CIRCL portfolio analysis team based on content reviews of CFLT projects across the years. Proposed tags are also included in project intake and exit surveys sent to Pls, who are asked to indicate which tags apply to their projects and/or suggest new tags. Since not all PIs respond to these surveys, the CIRCL team reviewed project abstracts and assigned tags when they were needed. Further, in 2018, the team conducted a major review of the full tag set and did some consolidation and retagging. 


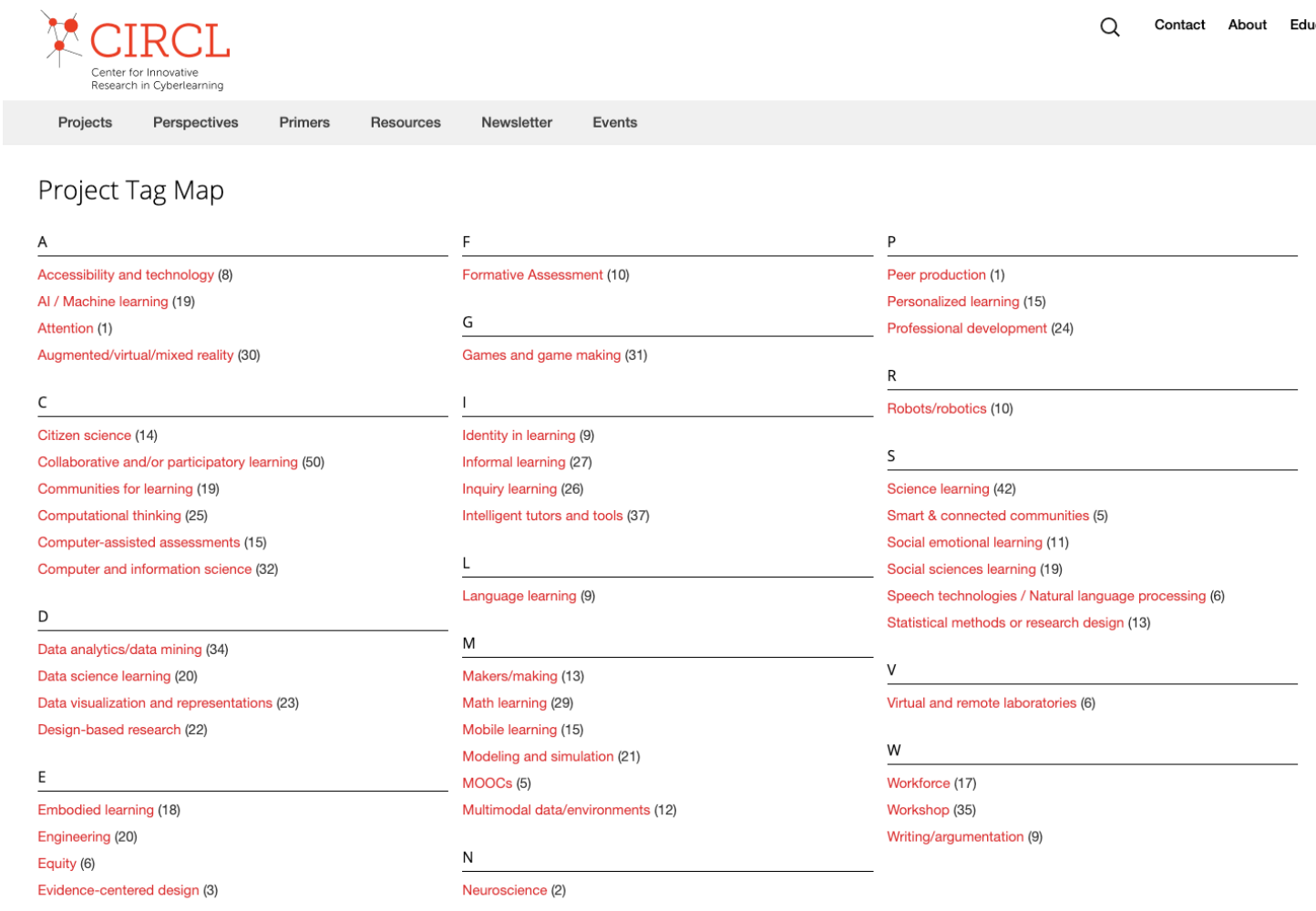

Figure 1: All project tags from the Project Tag Map on the CIRCL website.

\section{Common Tags - Project Tag Index}

\section{Computer and information science Games and game making Math learning Data analytics/data mining Inquiry learning Science learning Workshop Informal learning Collaborative and/or participatory learning Augmented/virtual/mixed reality Intelligent tutors and tools Professional development}

Figure 2: Sample project tags from tag cloud on CIRCL website.

For the Reflections analysis, the team counted unique tags across projects, created clusters of related tags and projects, discussed the counts and clustering results, and selected a set of themes for analysis. The themes emerged primarily from (bottom up, data driven) coding frequencies, but the CIRCL team's (top down) knowledge and experience doing the Cyberlearning Community Report also helped us think through important themes and meaningful clusters, influencing the process. For example, one tag that was frequently selected was Informal Learning, which indicated that many cyberlearning projects take place outside of the classroom. Our knowledge of the community helped us to understand that cyberlearning projects in formal education settings would likely be included in themes such as Learning Theories and Al \& Education and would not need to be under a separate theme. We decided to have an Informal Learning theme that included projects focused on making, 
citizen science, and interactive/mobile exhibits. On the advice of panelists, we changed the name to Out-of-School-Time, to be more accurate about the kinds of projects that were subsumed under this theme, since some could involve camps or afterschool programs that were not necessarily "informal" but which were not part of a standard school day. The theme, Emerging Trends, was derived from our (knowledge-driven) discussions of the themes and our understanding of external trends such as NSF Big Ideas, neuroscience and learning, and issues around equity and access.

Once the key themes were identified (see Table of Contents for the five themes), CIRCL team members organized as small group "theme teams," typically with 2 staff members per theme. We then assembled a large collection of relevant documents-including descriptions of all convening and workshop sessions and of all funded cyberlearning projects. We included documents written for or by CIRCL that appear on our website, such as Primers, Project Spotlights, and Perspectives. We also included STEM Video Showcase videos tagged with "cyberlearning." We coded each piece of information by theme and subtheme. For example, for the Al theme, subthemes included intelligent tutoring systems; machine learning; speech, vision, and naturalistic interaction; and social robots and avatars. Counts were tallied (see Figure 3), and theme teams examined the data for thematic changes over time and identified illustrative examples and highlights. Some teams also contacted individual Pls for their reflections on changes in themes over time.

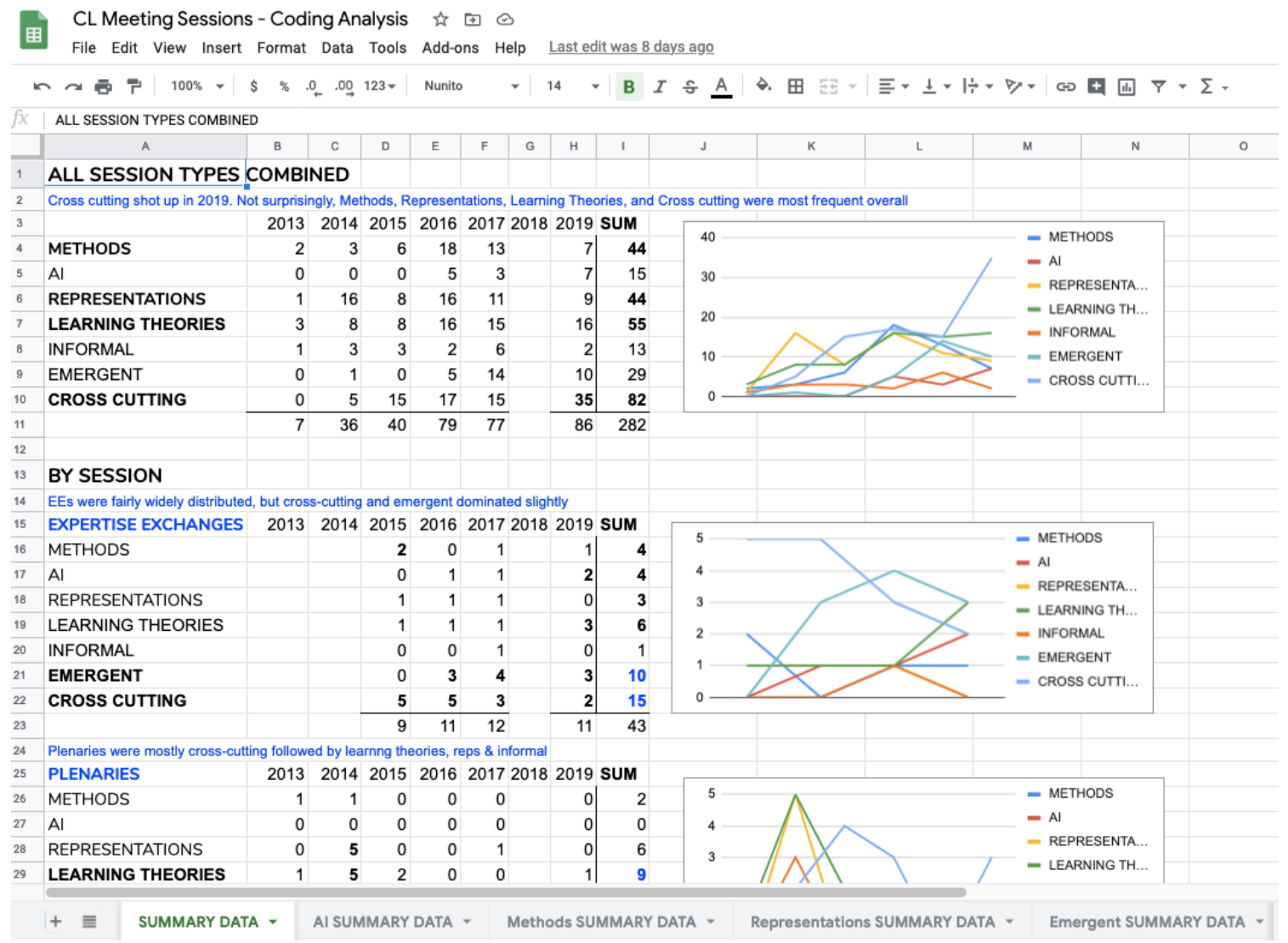

Figure 3: Analysis of themes by year and type of document or event. 
Finally, theme teams reviewed these documents and analyzed the content therein, which included the removal of "Representations" as a theme since it overlapped with existing themes. Based upon their review, they wrote up findings and reflections on their theme in draft Reflection Briefs, presented these briefs in a meeting of all CIRCL staff, and then revised the briefs based on team questions and feedback. Next, individuals on the CIRCL team were assigned to review at least one other team's brief, resulting in yet another round of revisions.

\section{Reflections Panel}

The resulting theme briefs were then shared with a "reflections panel" in a June 2020 workshop. The following panelists were invited and attended two half-days of meetings online. In a mix of large and small groups, they reviewed the briefs, reflected on the themes, and deliberated on their recommendations. The CIRCL team recorded these discussions and took considerable notes.

The panelists included both CIRCL's advisory panel as well as all former and present NSF program officers who have led cyberlearning research programs. Members are listed below.

- Guy-Alain Ammoussou, Bowie State University

- Amy Baylor, National Science Foundation

- Peter Brusilovsky, University of Pittsburgh

- John Cherniavsky, retired from the National Science Foundation

- Danny Edelson, BSCS Science Learning

- Chris Hoadley, New York University

- Sherry Hsi, Concord Consortium

- Ken Koedinger, Carnegie-Mellon University

- Janet Kolodner, Boston College

- Tanya Korelsky, National Science Foundation

- Stephanie Teasley, University of Michigan

- Erin Walker, University of Pittsburgh

After the expert panel, authors of each brief revised their drafts based on input from panelists and added a new section to their brief summarizing conclusions and recommendations from the panel. The final versions of the briefs are presented as the five themes of this report.

\section{History of the Cyberlearning Program}

At the beginning of our expert panel meeting for this reflections process, we asked panelists to tell the group about their experience with the Cyberlearning program and what they imagined it would be. We learned about their perspectives on the program at the different points in which they played a role in its development. Together, their comments told the history of how the program was created and how it evolved over time.

Before there was a Cyberlearning program there was another collaboration between NSF's Directorate for Computer and Information Science and Engineering (CISE) and the Directorate for Education and Human Resources (EHR) called Advanced Learning Technologies (ALT) that ran from 2005-2009. Prior to ALT, there were other initiatives in learning technologies such as "Learning and Intelligent Systems" and "Collaborative Research in Learning Technologies (CRLT)." With the advocacy of NSF from both directorates, including Haym Hirsh, John Cherniavsky, Amy Baylor, Elizabeth Vanderputten, and Ken 
Whang, and under the leadership of assistant directors Jeannette Wing (CISE) and Joan Ferrini-Mundy (EHR), funding was secured from Congress for what was newly referred to as "cyberlearning." In 2010, a Task Force on Cyberlearning and Workforce Development was commissioned to gather information from researchers from a number of different fields about what NSF could do to create a 21st century workforce that would be cyberinfrastructure savvy. This taskforce produced a report ${ }^{1}$ which included many recommendations, one of which was:

\begin{abstract}
We recommend support for research in cyberlearning. The NSF should devote significant resources to research and development in cyberlearning, exploring meaningful metrics for assessing the needs and progress of all learners by the learner, educator, and others, and the learning impacts of cyberlearning resources and opportunities. A solid body of professional research evidence and development work is needed before cyberlearning tools can be effectively implemented across the learning spectrum, maximizing positive impacts while minimizing unintended consequences.
\end{abstract}

Starting in 2011, NSF created a new program specifically to fund cyberlearning research. Janet Kolodner was asked to lead it. "When I first heard about the program, I thought it was simply about technology for online education, and that didn't interest me so much," said Kolodner. "But then I learned Jeanette and others had more in mind and that they wanted to give me a chance to make it interesting." Kolodner drew upon her experience as faculty at Georgia Tech and editor of the Journal of the Learning Sciences to create a program, which became Cyberlearning and the Future of Learning Technologies (CFLT). A solicitation was created encouraging the submission of proposals for innovative technology projects that explored how learning theories played out in educational contexts. The program funded design projects that represented multiple disciplines and technologies that were more exploratory than many of the projects funded by other NSF programs. The program also looked to produce findings that would generalize beyond the particulars of the current exploration. In 2013, the Center for Innovative Research in Cyberlearning (CIRCL) was established to support this new community of interdisciplinary researchers.

In 2014, Kolodner left NSF and Christopher Hoadley, a rotator from New York University, became the lead program officer for CFLT. The program continued to encourage design projects that focused on big ideas in learning theory. Hoadley also made an effort to bring together the cognitive science, computer science, and learning sciences communities, recommending that researchers crafting proposals for the program read the latest research in all of these fields as well as the design field and use that to inform their projects. "We needed to center on design," Hoadley said, "not only rigor and theoretical ideas, and not just a kitchen sink of ideas. We needed designs that would really help us to build knowledge and understanding of the technological possibilities that would become available in the future." There was less of an emphasis on research that produced scalable, generalizable results and more encouragement to explore challenging ideas and advancements in designing coherent innovative integrations of technology, computer science and learning theory.

In 2016, NSF came out with their ten Big Ideas for investment, which had a major influence on the emphasis given to many programs, including cyberlearning. The Big Ideas that had the

\footnotetext{
${ }^{1}$ Task Force on Cyberlearning and Workforce Development (2011). A Report of the National Science Foundation Advisory Committee for Cyberinfrastructure.

https://www.nsf.gov/cise/oac/taskforces/TaskForceReport_Learning.pdf
} 
most relevance for cyberlearning were INCLUDES-with its focus on systematic approaches to broadening participation in the STEM workforce-the Future of Work at the Human-

Technology Frontier, Convergent Research, and Harnessing the Data Revolution for 21st Century Science and Engineering. Senior advisor for the Cyberlearning program, John Cherniavsky, was particularly interested in this last idea. "I came to the program from a long background in new computer science advances," said Cherniavsky. "As I came on board, big data and learning analytics were areas of research that were accelerating rapidly. One of my main interests is in tools, and thus cyberlearning expanded to include analytic tools that would become important parts of the designs of future technologies for learning."

Also, in 2016 Hoadley finished his rotation at NSF. Because Cyberlearning is a crossdirectorate program funded primarily and led jointly by CISE and EHR (with collaboration from Directorates for Social, Behavioral and Economic Sciences (SBE) and Engineering (ENG), the directorates decided to have co-program leads from both CISE (Tatiana (Tanya) Korelsky) and EHR (Amy Baylor). "The field of cyberlearning had strong foundations built on the fantastic ideas and contributions from Janet, Chris, John and CIRCL when Tanya and I took over to co-lead the program," said Baylor. "Unfortunately, the budget had been significantly cut, and we focused on honing the specific, differentiated value of this program. Many existing programs in EHR were already funding educational technology implementation projects. We focused cyberlearning on exploratory projects that were risky, ambitious, and that innovated in both the learning and computer sciences, which was important for our partnerships with CISE and ENG."

Also, during our time, the NSF Big Ideas were developed by the NSF Director Francis Cordova, and NSF used that opportunity to challenge the field and connect cyberlearning to one Big Idea in particular, "Future of Work at the Human-Technology Frontier." These led to increased visibility of the program across the Foundation and facilitated a larger budget. The name of the program changed to Cyberlearning for Work at the Human-Technology Frontier. In addition, to emphasize the innovative and experimental nature of the program, the new iteration only funded exploratory projects, rather than supporting a range of exploratory, development, implementation, and scale up projects, as other programs do. "We really focused on exploratory work as an important nexus for computer science and learning scientists to come together," Korelsky said. "We wanted to understand how technology affected the learning process; especially with very novel technologies. We emphasized a midsized project with a budget big enough for both a computer science and a learning sciences graduate student to be engaged together." Even though the program continued to fund cyberlearning research in all areas (not just in the context of work), Korelsky also noted that having "work" in the program title led to fewer proposals being submitted. The ones however that were submitted were high quality and used innovative approaches to connect learning with workforce preparation through technology integration.

Now with new NSF director Sethuraman Panchanathan replacing France Cordova, there will be new areas of research that he will want the directorates to pursue and those priorities will certainly have an impact on the Cyberlearning program. However, the program's particular strength in bringing diverse disciplines together to create innovative ways to support learning will likely continue to be valued by the larger NSF community. As one of the original advisory board members, Daniel Edelson stated, "Talented experts in non-education fields often develop innovative ideas for improving education. Where the Cyberlearning program has done an exceptional job is in helping innovative newcomers to develop partnerships with learning scientists to develop theory-informed designs and to investigate how those designs 
support learning." Since the program's founding it has been able to adapt to new trends and priorities while maintaining its core value of building knowledge within educational programs informed by learning theories. This adaptability is a testament to the ingenuity of the community of researchers that the Cyberlearning program and CIRCL have cultivated and supported and will continue to support into the future.

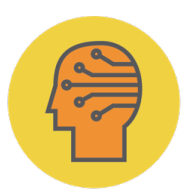

\section{Theme 1: Artificial Intelligence \& Learning}

Authors: Jeremy Roschelle \& Patricia Schank; Contributors: Judi Fusco \& Wendy Martin

\section{Definition}

Cyberlearning projects advance state of the art technologies and techniques from computer science, data science, robotics, and other areas. In conjunction with learning scientists and experts in equity and in particular subject matter or educational contexts, cyberlearning projects seek to advance our understanding of these technologies and techniques in the context of human learning challenges. In reviewing the portfolio, the most common types of technologies and techniques are:

- Intelligent Tutoring Systems, in which a computational agent supports and guides students as they work to learn challenging subject matter.

- Machine Learning, where statistical techniques are applied to infer patterns in large data sets about learner behavior and outcomes. Insights and techniques for guiding learner's behavior to desired outcomes are sought.

- Speech, Vision, and Natural Interaction, where machine learning and other techniques are specifically applied to analyze human speech, visual scenes in which learners participate, eye-gaze, etc. and (in cases) to synthesize naturalistic interactions with learners in the same modalities.

- Social Robotics and Avatars, where above techniques are applied to provide an artificial learning partner to a student or group of students.

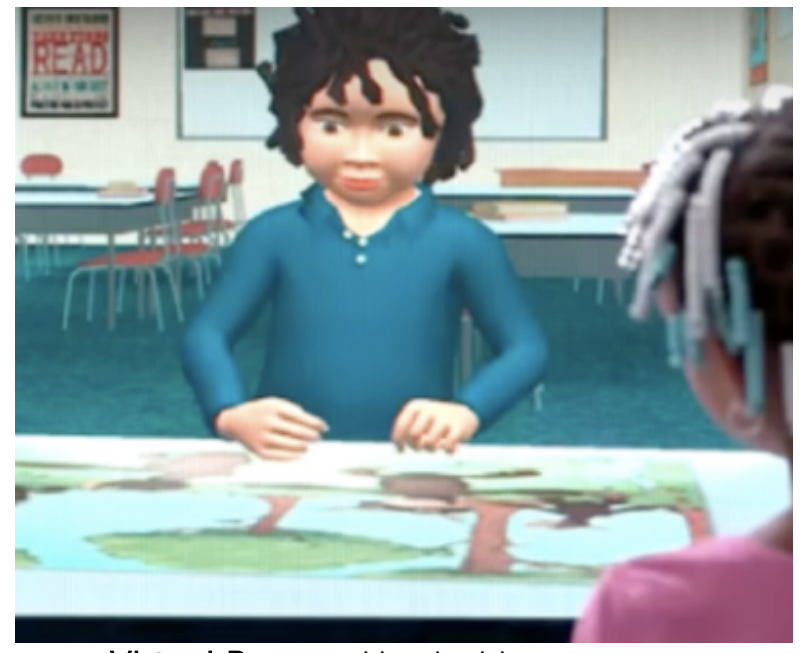

Virtual Peers - Used with permission of Justine Cassell

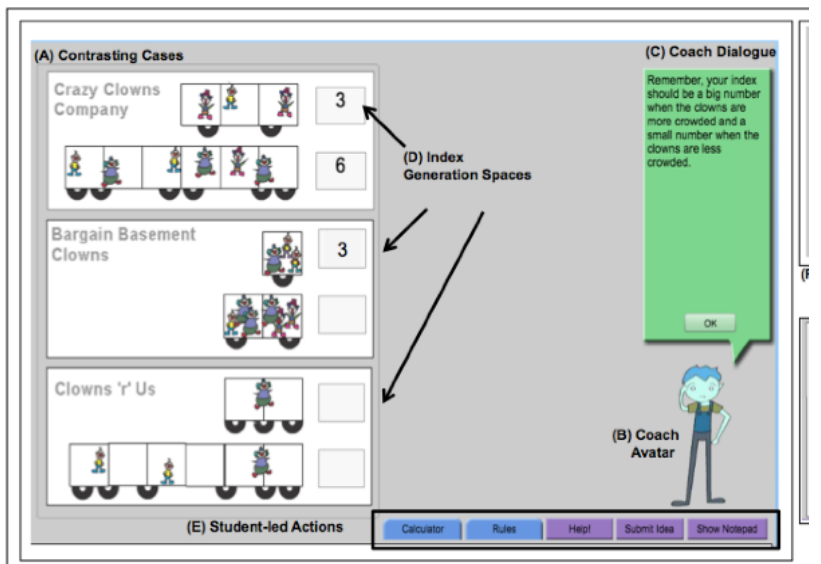

Invention Coach Main Interface. The goal of the task is to invent an index of "clown crowdedness" for each of the buses in $t$ receive support from the Coach (B) in the dialogue box (C), and input their ideas into index generation spaces (D). Additional
the calculator $(F)$, taking notes in the notepad (G), reviewing the rules $(H)$, or soliciting help from the coach by clicking "Helpl"

Invention Coach ITS - Used with permission of Catherine Chase 


\section{Change over Time}

The Artificial Intelligence (Al) \& Education community is long-standing and accomplished, with its own society, journals, and multiple funding streams. As participants in the cyberlearning community, experts in the above topics were somewhat less present in the first 3-4 years, but participation increased strongly thereafter. Rather than simply advancing Intelligent Tutoring Systems (ITS) technology with Al, cyberlearning projects combine Al with learning theories to create "ambitious mashups." Examples include exploring hybrid systems in which people and Al agents work together, focusing on social learning (classic Al \& Ed research was somewhat more individual-oriented. Cyberlearning Al projects also support teachers and expand to applications like social robots for learning Chinese, Al supports for workforce learning, and an invention coach (whereas early ITS applications were often oriented to more bounded problem solving in math and science). Thus, the portfolio of cyberlearning projects push beyond Al beyond the boundaries of a conventional ITS.

Another important body of cyberlearning research is not framed relative to an ITS or a "tutor" but rather to automated analysis of the complex human activity of learning. Understanding speech patterns in collaboration is one example. Automatically analyzing videos of preschool teachers and children is another. Assessment applications also were pursued, where the analysis of naturalistic input can inform us as to what a student knows and can do. A need for relevant corpus of data was often discussed.

An emergent and important initiative in the community has been to propose open platforms that could support multiple investigators in more efficiently experimenting with Al, Machine Learning, and Natural Language techniques (rather than each investigator building their own soup-to-nuts learning environment). ASSISTments is a platform example that was talked about early and often in Cyberlearning convenings, as was LearnLab from CMU. Other potential platforms could include science "workbench" type learning environments, shared robots platforms, MOOCS, large scale curricular resources (like AlgebraNation) and also museum experiences (like Connected Worlds) that are instrumented to provide data to multiple researchers.

At the 2018 joint meeting of ICLS, Al \& Ed, Learning at Scale, and the Cyberlearning 2019 convening, issues of fairness, privacy, accountability, transparency, and equity came up very strongly as issues the cyberlearning community wants to work toward resolving. A 2020 NSF call for large Al Institutes drew much participation from cyberlearning researchers.

\section{Reflection Starters}

Questions posed to a panel of CIRCL advisors and current and former NSF Cyberlearning Program Officers for discussion:

- Al \& Education has been a long-standing field with multiple funding streams, of which cyberlearning funding is a relatively small amount. Is there potential for unique contributions from cyberlearning? How could this community advance Al in Learning beyond what happens in other work streams?

- Educational settings can present important fundamental challenges for speech, vision, and naturalistic interaction; how could cyberlearning's potential contribution be strengthened? 
- This area is advancing very rapidly and is very technically demanding; what do these projects tell us about how other areas of cyberlearning can include cutting edge CS expertise?

- What issues related to Al and fairness, accountability, transparency, and equity need to be considered in the future? Is this the place for it? Do solicitations need to specifically call for this?

\section{Recommendations from the Reflections Panel}

Cyberlearning researchers are in a unique position to encourage and enable more humancentered $\mathrm{Al}$ and hybrid Al systems-for example, with teachers in the loop across all phases of system development and use. Recommendations from the panel included:

- Empower and involve teachers (in addition to subject matter experts, learning scientists, and technologists) from the beginning as co-designers of Al-based intelligent systems.

- Enable teachers to train and correct the system as it responds incorrectly or inappropriately.

- Teachers and students should also be given agency to interpret and potentially override a system's recommendations.

- Projects should identify meaningful, inclusive partnerships at the research level with practitioners and institutions that serve underrepresented minorities during the proposal-writing phase.

- An NSF-funded Al \& Education resource center should help projects by brokering connections to broaden participation and to help connect learning research with new fundamental capabilities in artificial intelligence, which is a rapidly evolving field.

\section{Project Examples and Resources}

For project examples, resources, and links, visit: https://circlcenter.org/resources/reflectionsreport/ai/. From this site, you will be able to review project abstracts, read related publications, and view videos produced by the projects. 


\section{Theme 2: Learning Theories}

Authors: Judi Fusco \& Jeremy Roschelle; Contributor: Patricia Schank

\section{Definition}

Theories of how people learn are an integral part of cyberlearning research. Projects interweave learning theories with emerging technology and research methods to uncover processes of how learning unfolds with theoretical depth and empirical precision in service of new theories of learning. Cyberlearning projects also use principles of how people learn to support learning in STEM (for example astronomy, data science, biology), topics beyond STEM (language learning, reading, writing) and workforce skills. In this review, the following three areas in learning theories were considered:

- Collaborative Learning. Collaborative learning examines how people learn socially through shared words, actions, and meanings. In cyberlearning, collaborative learning occurs when the tool or environment for learning is social. The concept of collaborative learning is broad and includes collective inquiry, knowledge building, joint problem solving, intersubjectivity, shared/collective/group/distributed cognition, collective consciousness, and transactive discourse. From a constructivist perspective, learning occurs as participants make sense of their experience.

- Embodied Learning. Embodied learning theories seek to understand how movements, gestures, and actions influence learning. In cyberlearning, embodied design guides the integration of gesture and technology; for example, virtual tutors gesture in interactions with learners and technologies recognize movements that are used in relation to concepts.

- Identity. Sociocultural theories examine how a person forms their own identity situationally, and how learning is about developing identity (not just knowledge or skill). Identity development includes seeking to understand how you think of yourself, your perception of how others see you, and what perspective is promoted by society.

Among all themes examined in our reflection analysis, "learning theories" was the second most frequent tag for cyberlearning convening sessions. While here we focus on the three sub-areas above, other long-standing scientific theories also have a strong place in cyberlearning work. For example, cognitive theories are not explicitly included here, although cognitive theories often inform projects with respect to representations (e.g., games, simulations, and visualizations), methods, and Al (e.g., learning analytics and intelligent tutoring systems), and collaborative learning. Projects guided by neuroscience theories are discussed in the External Trends brief, but also overlap with projects tagged with embodied learning. 


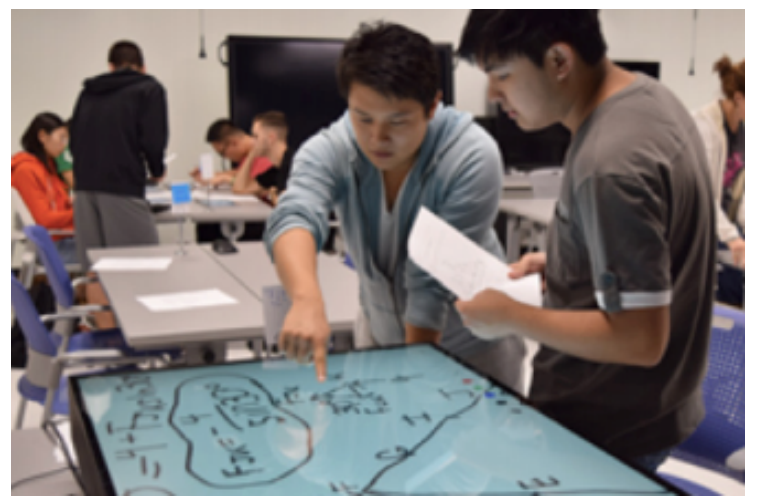

Co-constructing solutions Used with permission of Emma Mercier

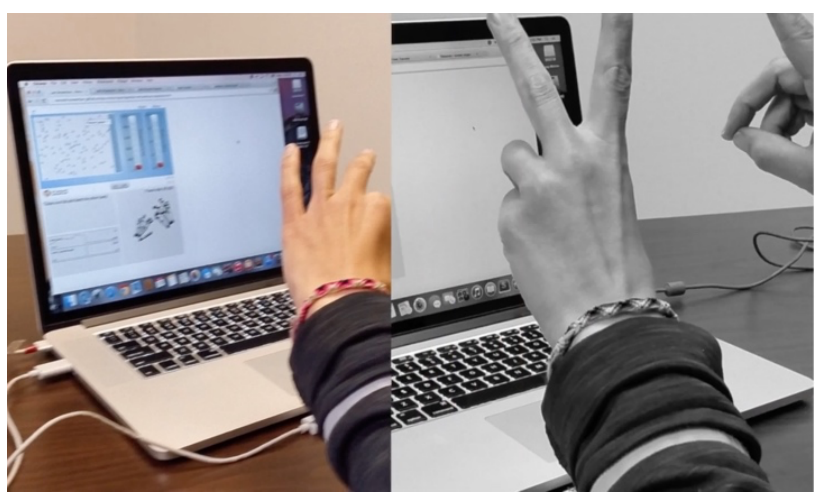

Gesture Augmented Simulations for Supporting Explanations (GRASP) Used with permission of Robb Lindgren

\section{Change over Time}

Collaborative Learning was seen in 36 funded projects, addressing a diverse set of topics including intelligent tutoring systems, learning analytics, robots to help teach collaboration skills, and augmenting work in maker spaces, workplaces, and citizen science. In many of these projects, the innovation comes from leveraging collaborative learning in new ways with new technologies. In other projects, the innovation has come through deepening a theory of collaboration-for example, developing the concept of orchestration or advancing knowledge building theory (e.g., in Jianwei Zhang's Thread Mapper and Tom Moher's instrumented classroom). In orchestration work, advances have supported ensembles of people taking on different roles rather than one person directing tasks. Other projects have advanced our understanding around how to connect people and ideas across settings (Erin Walker's ubiquitous collaboration technology), or how people and Al-such as conversational agents and robots-can work together. Technologies for supporting advances in collaborative interfaces include immersive experiences, such as AR and VR; voice-driven systems; tangible computing; tabletop devices; language processing; collaborative sketching; and digital ink.

Embodied Learning was seen in 15 funded projects. As technologies such as VR, AR, and haptic feedback have become more sophisticated and allow the tracking of learner's movement, many "ambitious mashups" guided by learning theories have emerged and evolved over the years. Early projects sometimes involved learners moving objects on iPads, or experimented with wearable technologies. More recent projects took advantage of emerging technologies to analyze movement in more sophisticated ways (using methods informed by learning analytics) and provide feedback to learners (through an ITS or virtual tutor). One recent project gives a "minds-on" bridge between ideas and writing using motion-tracking, sketch-recognition, and animation technologies (see Digitally-Augmented Enactment). Settings for embodied projects range from helping improve reading for ELL students, computational thinking, mathematics, and science, and to enhance remote learning; participants ranged from young children to adults in the workforce.

Theories of Identity were strongly addressed in 9 projects, often focusing on how participants' identities changed through the project work. For some learners, their identity is 
very different in home and school situations; many projects investigated how to connect their learning across contexts. Additionally, games and virtual coaches have been used to help shift habits, dispositions, and behaviors in learners. For example, the Developing STEM Identities project investigated the intersection of technology, pedagogy, and learning by creating new classroom activities to foster learning for students and to help instructors discover new approaches and support their students. Generally, the work done in identity has illustrated the broader context that is important to consider to understand and influence learning. Cyberlearning has also funded capacity building work to bridge sociocultural theories and bring them to the fore in cyberlearning work. Distinct work in equity-related to identity -is being done in work on Smart and Connected Communities for Learning, and interest-driven learning (e.g., FUSE).

\section{Reflection Starters}

- In what ways has cyberlearning pushed learning theory forward? How could or should cyberlearning research seek to develop learning theory in the future?

- Do we now better understand the "zone of proximal development" where emerging technology, learning theory, and equity each have a powerful and mutually informative voice? Can we make a stronger case for why research on learning technologies that are 5-10 years out should include research that develops, refines, and/ or clarifies new theory?

- The body of cyberlearning work is theoretically diverse. Does it make sense for the conversation to spend more time on a few constructs (like those above) or should there be a more pluralistic way of working with the theoretical diversity? How do we choose what gets the "floor" in community events?

\section{Recommendations from the Reflections Panel}

Panelists described theory as highly important in cyberlearning research, to guide design, to enable analysis of learning processes, and to work towards generalization. Panelists recommended further clarification of the nature of the interdisciplinary theory development work that occurs in exploratory, future-oriented research, and the potential outputs of this work.

- Articulating and explaining the most common important theories and stances in cyberlearning research will strengthen the field and help it to communicate. These include the areas of theory above as well as additional ones (e.g. panelists noted cognitive and human-computer interaction theories are prominent in the work)

- This research community has notable opportunities to refine theories in relationship to design of novel learning environments and how designs can be implemented in varied education settings.

- The research community has a strong opportunity to use theory in its explorations to generate stronger hypotheses about what can make learning more equitable in the future.

- It is important to see theory-building as convergent work of interdisciplinary research teams, rather than only the work of learning scientists or just one PI.

- Exploring innovative learning tools and new forms of data (e.g. multimodal analytics) may open up or transform potential research questions, and thus influence many more researchers. 
Ultimately, panelists were wary about the tendencies of the overall educational technology field to promote platforms and tools with weak or absent theory. Cyberlearning research has an important opportunity to further develop learning theories so they are highly relevant to the design of future learning technologies and also are rigorously grounded in larger bodies of theory and in empirical data.

\section{Project Examples and Resources}

For project examples, resources, and links, visit: https://circlcenter.org/resources/reflectionsreport/learning-theories/. From this site, you will be able to review project abstracts, read related publications, and view videos produced by the projects. 


\section{Theme 3: Research Methods}

Authors: Judi Fusco \& Patricia Schank; Contributor: Jeremy Roschelle

"I see exciting possibilities in cyberlearning for thinking about tool design and analytics design together, such that learning environments produce useful data and are designed to take advantage of the data to support teachers and students as well as their own continual self-improvement."

- Alyssa Wise (excerpt from 6/1/20 reflections on her work and field)

\section{Definition}

Cyberlearning projects explore the frontiers of learning with technology, and to do so, the methods they use need to be innovative and informative. While methods are part of every project, they sometimes become the prime focus of the project-for example, when the methods are uniquely innovative or being refined as part of the work. Even established methods can take center stage when they deeply shape the work being done. Because of the interdisciplinarity of cyberlearning projects, we also see methods from different fields combined in new ways to provide insights to questions. In reviewing the portfolio, the most common or growing methodological approaches found were:

- Design-Based Research (DBR). Researchers create learning experiences and study them to investigate potential advances and to better understand what the target users and communities need. In cyberlearning, DBR is a methodology that rigorously explores which design features have the most potential to improve learning.

- Learning Analytics. Learning analytics can provide insights to the learning process and are often linked to formative assessment, sometimes in Intelligent Tutoring Systems (ITS), to provide students with direct feedback and/or give teachers more information to help their students. In addition, learning analytics have been used to support group problem solving by helping learners acquire content knowledge or to support collaborative processes.

- Multimodal Analytics. Building on learning analytics, multimodal analytics is a method that involves the integration and analysis of multiple data sources (e.g., visual, audio, gestural, movement, eye gaze, heart rate, and/or other types) to help researchers measure learning in new ways and gain insight into learners' abilities, emotions, needs, and preferences and how these impact learning interventions.

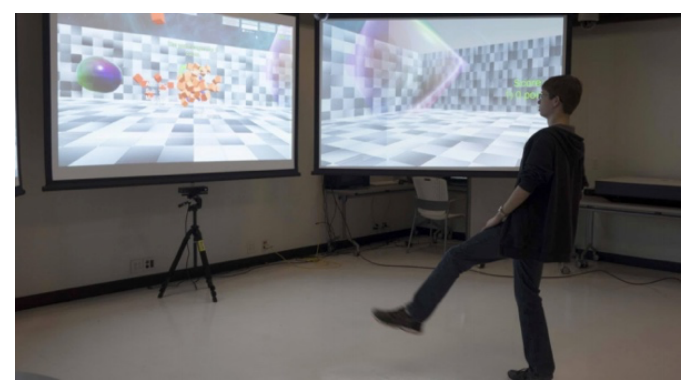

Multimodal sensors - Used with permission of Robb Lindgren

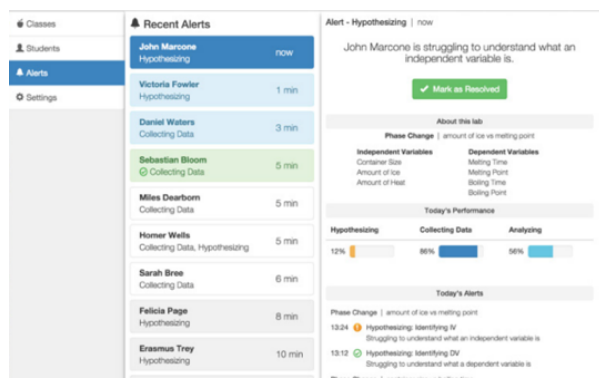

Inq-Blotter dashboard - Used with permission of Janice Gobert 


\section{Change over Time}

DBR was an important part of 22 funded projects and a focus of 4 Cyberlearning sessions across the years. Relative to its prevalence in project work, it was highlighted less in convening sessions, possibly because it is a well-developed method that many learning scientists use to understand engagement and learning in a project. In the 2017 Cyberlearning Community Report, a chapter was devoted to new work bringing together HumanComputer Interaction ( $\mathrm{HCl}$ ) methods and DBR methods to 1) better involve stakeholders, 2) help maintain a focus on equity, and 3) explore tensions between making technology easy to use and supporting the learning process.

Learning Analytics was found to be part of 34 projects and 14 Cyberlearning convening sessions over the years. More established than multimodal analytics, less established than DBR, and rapidly evolving (e.g., with Big Data and Al technology), this method was commonly highlighted in both project work and convenings. The term itself has also evolved over the years; "learning analytics" is commonly used in the cyberlearning community, but work in this category is sometimes called "educational data mining" or "big data" (especially in earlier years) - and in 2018 and 2019, the term Multimodal Learning Analytics (MLA) came into common usage. Work in the learning analytics category is often guided by cognitive theories of how people learn; however, some projects are exploring non-cognitive factors (e.g., Developing Community \& Capacity to Measure Noncognitive Factors in Digital Learning Environments). At the 2018 "Festival of Learning" conferences in London, learning scientists, $\mathrm{Al}$ and Ed researchers, and computer scientists who study "learning at scale" argued that learning analytics still needs much stronger connections to learning theories and to rapidly evolving learning environments; in many cases, applications of analytics address learning but use readily observable characteristics of learning without a learning theory. Recently, one of the nine Cyberlearning workshops on Principles for the Design of Digital STEM Learning Environments focused on Research Priorities in Learning Analytics. The workshop brought together scholars with expertise not yet connected with learning research, including data scientists who have made contributions in other parts of the economy, with members of the business community who use "people analytics" and other methods for looking at competence.

Multimodal Analytics was incorporated in roughly a dozen funded projects and five Cyberlearning convenings sessions across the years. Relative to its prevalence in project work, it was highlighted more in convening sessions, probably because it is a new, evolving method that many participants wanted to learn about. In the Community Report, it was featured as an innovative method that integrates multiple data types, including those related to emotion and movement, to help researchers better understand learning in multimodal and embodied learning environments. Recently, this was the focus of a report from a workshop, which noted that while multimodal sensing holds promise for better understanding learning and motivation, there are technical challenges to such investigation as well as the potential to disrupt the learning context altogether due to the intrusive presence of the sensors and instruments. In addition, there are challenges to understanding what students are thinking from the instrument-collected and automatically analyzed data for knowing when and how to intervene. 


\section{Reflection Starters}

- What investigations do these methodologies enable or help us to advance in cyberlearning? Pushing the boundaries of methods for studying learning has not been prominent in CL solicitations; should the community push for more visibility of the importance of advancing methods so that we can better study learning in future learning environments?

- What methods really fit a community that is exploring "ambitious mashups"? What are the missed opportunities or latent possibilities to further develop these combinations?

- Learning analytics and educational data mining have societies, journals, conferenceswhat is unique about the cyberlearning community as a place for methods development?

- Designing for better learning data. How can we accelerate the move from easily available data to designing systems that can generate more meaningful data to understand learning? Given "ambitious mashups" in methods as well as in learning environment design, is this what "convergence research" (an NSF Big Idea) should mean to the cyberlearning community? (e.g., can we define convergence research in this area in terms of the need to advance methods)?

\section{Recommendations from the Reflections Panel}

The discussion ranged from "what methods are important in cyberlearning" to "what makes something a method". The panel suggested thinking about how technology can lead to advances in: 1) methodologies required for research in learning, and 2) methodologies for design and implementation. The panel noted that though computational methods were used frequently, projects that use sociocultural and sociopolitical methods should not be overlooked. Additionally, they noted there may be a slight shift towards doing research in cyberlearning on shared platforms, and that these could offer data and design infrastructure. Some key conclusions and recommendations from the panel were:

- A strength of cyberlearning is the cross pollination from multiple fields, such as education, computer science, $\mathrm{HCl}$, and practice. Convergent science that also crossfertilizes methods can be very productive and lead to new insights.

- The field should continue to triangulate multiple, mixed methods (computational, quantitative, qualitative, multimodal, etc. analyses) to increase validity in the investigation of learning through the convergence of information across different learners, contexts, and data.

- People think what comes out of computational analyses is objective, when it's not. Humans create the algorithms and collect the data, and humans have bias. As Alyssa Wise (CFLT PI) notes in her reflection, "The field needs to be explicit about the roles of human decision making in data mining processes."

In generalizing models of learning, we need to be careful: Models are built based on data and methods used with a particular population of learners. Assuming that a model generalizes to other populations could perpetuate inequities even if we are trying to broaden participation. 


\section{Project Examples and Resources}

For project examples, resources, and links, visit: https://circlcenter.org/resources/reflectionsreport/methods/. From this site, you will be able to review project abstracts, read related publications, and view videos produced by the projects. 


\title{
Theme 4: Out-of-school-time (OST) Learning
}

\author{
Author: Wendy Martin; Contributor: Patricia Schank
}

\section{Definition}

Many cyberlearning researchers design projects for learning contexts outside of formal schooling, such as museums, makerspaces, libraries, and in afterschool programs that may be located in schools or other locations. These settings are often more open than formal settings to the integration and exploration of innovative technologies and learning theories. Out-of-school-time (OST) learning experiences tend to be playful, interest-driven, and intrinsically motivated, allowing for engagement in authentic practices that can lead to social-emotional as well as content and skills learning. OST learning formats can sometimes be cross-context, multigenerational, and community oriented. Cyberlearning projects in OST environments have used a range of technologies for multiple purposes such as data collection, artifact creation, documentation, and sharing/collaboration. Cyberlearning research in OST settings has built knowledge about how youth develop STEM identities through engagement with STEM content and practitioners across settings, about how communities co-construct meaning from data, and how youth can develop persistence and agency through iterative design. Some typical types of cyberlearning informal projects include:

- Making, which involves creative, interest-driven tinkering and building with a wide range of materials from high tech (3D printers, laser cutters, Arduinos) and low tech (hammers, wood, fabric, glue, paper). These often, but not always, take place in makerspaces, dedicated facilities with a variety of materials and tools available to produce artifacts.

- Citizen Science, which has learners in the community collecting data about some aspect of the community or environment and sharing it with researchers and peer citizen scientists. Sometimes learners engage in data analysis as well as developing the research questions so the data can be used to achieve a community goal.

- Interactive/Mobile Exhibits, which can take place in a variety of settings, though most often in museums or cultural centers, but also community organizations, parks, and other gathering places. These exhibits draw on technologies such as augmented reality (AR), virtual reality (VR), mobile computing, or touch screens to create immersive and/or multi-sensory experiences. 

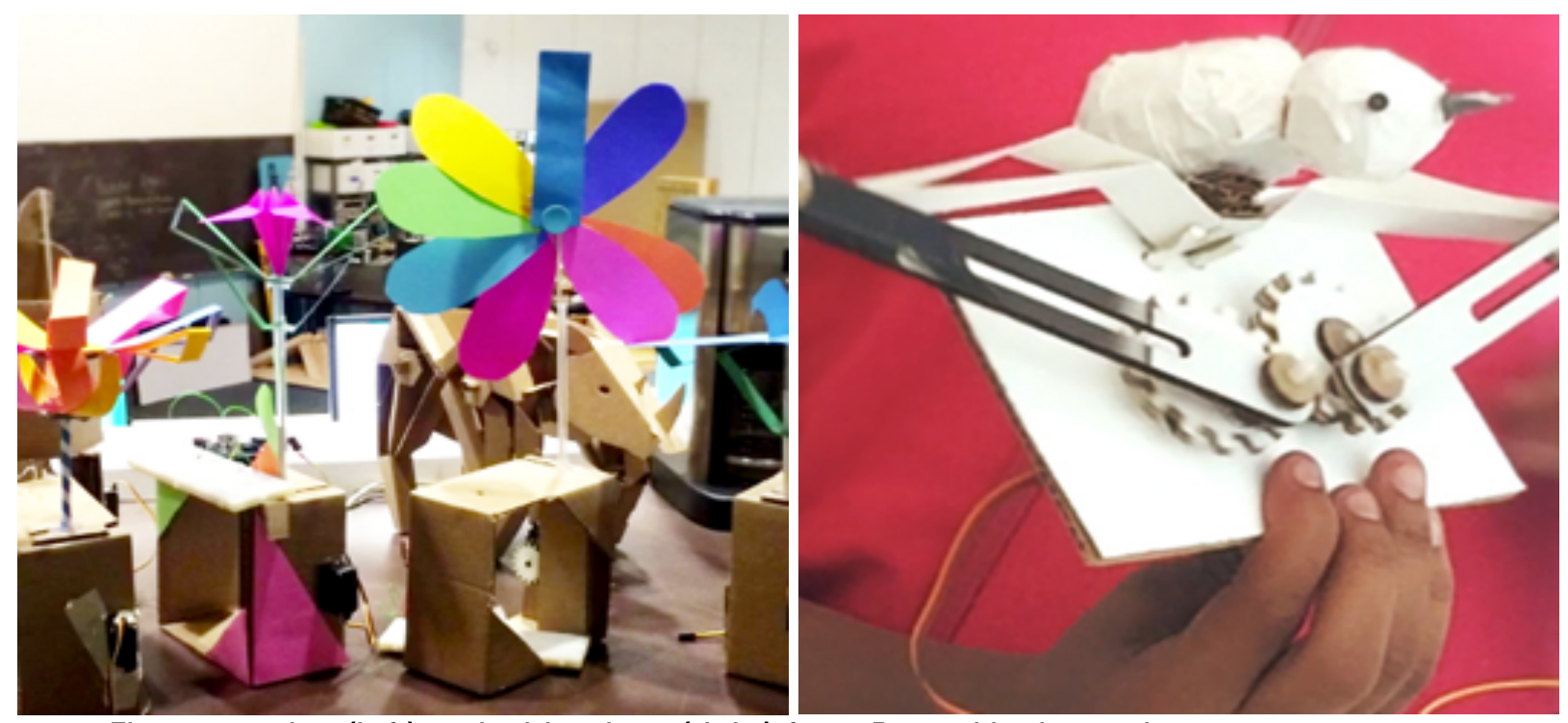

Flower garden (left) and white dove (right) from Paper Mechatronics- Used with permission of HyunJoo Oh

\section{Change over time}

In the first years of cyberlearning, the projects for OST education settings varied widely, from serious games to social robots, digital badges, and wearable computers to making, citizen science, and innovative exhibits. The learning theories they were based on tended to be around identity development, motivation, agency and collaboration. When NSF came out with its 10 Big Ideas, this eclectic group of projects appeared to shift into a more coherent set of learning experiences with specific underlying purposes. Big ideas of particular relevance were Harnessing the Data Revolution, NSF INCLUDES, Work at the Human Technology Frontier, and Growing Convergence Research-as well as the Smart and Connected Communities effort. These ideas provided guidance to the community to place an emphasis on using data analytics, broadening participation, connecting to workforce opportunities, creating innovative partnerships, and designing cross-context learning experiences.

Cyberlearning projects that focused on making transitioned from understanding how to support and measure learning in makerspaces to creating maker environments for a purpose, like social justice, or reaching particular communities, as well as using making in hybrid formal and informal environments. Some relevant projects include Paper Mechatronics, which started with an innovative way to combine high and low tech materials to provide creative, low-cost tinkering experiences and evolved to have a sharper focus on supporting engineering education for participants. In addition, early efforts such as Learning in the Making focused on understanding how to design and evaluate makerspaces, while newer projects are more "ambitious mashups"-such as Mentoring through Embodied Communications, which uses social, remote robots to support maker-based career and technical education (CTE) programming for low-income youth in US-Mexico border towns, and the Instrumented Learning Spaces workshop, which used innovative data collection tools to gather data on participant experiences in makerspaces.

Citizen science has been a consistent approach in cyberlearning, but now projects do much more than just collect and share data: they use technologies to enhance mobility and data 
collection across environments, and leverage backend data for modeling datasets or learning about the users. The transformation of the WeatherBlur project is a good example. This project began by using technology to create a non-hierarchical community of learners gathering climate and other environmental data in Maine and Alaska to support those local communities. Recent funding has been used to make it a platform that embeds more backend data collection and analysis to support the user experience, build models of users' skills and beliefs, and respond to their needs.

Changes in projects related to interactive or mobile exhibits can be seen in the evolution of the Connected Worlds exhibit at New York Hall of Science (NYSCI). This is a large-scale exhibit that has visitors interact with wall-size touch screens of fanciful animal and plant life to learn about the interconnectedness of ecosystems. NYSCI received support to hold a convening about how to use the data from tech-infused exhibits to conduct research on visitor experiences, and then received a grant to add this form of data analytics to their existing exhibit. NYSCI also worked with University of Washington on Mobile City Science to combine aspects of the virtual museum exhibit experience and citizen science by having youth learn about and collect data on their communities through mobile computing and augmented reality.

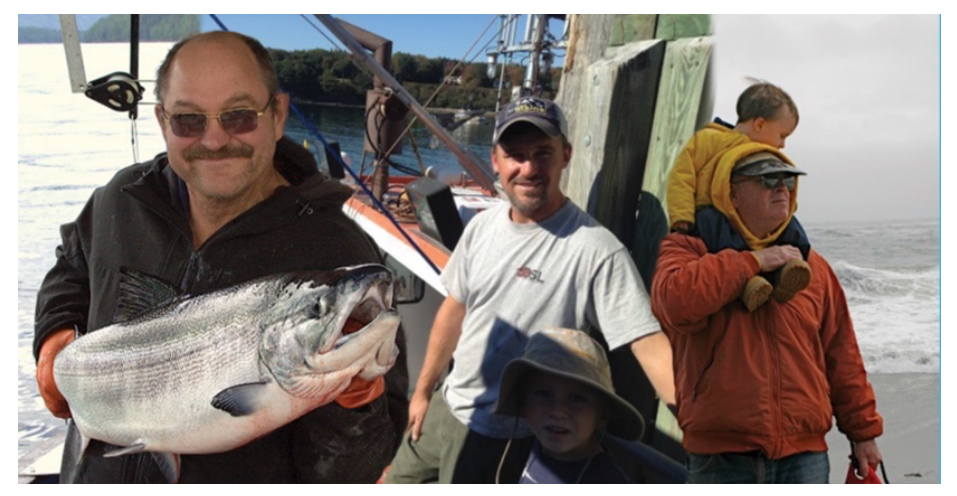

The WeatherBlur project - Used with permission of Ruth Kermish-Allen

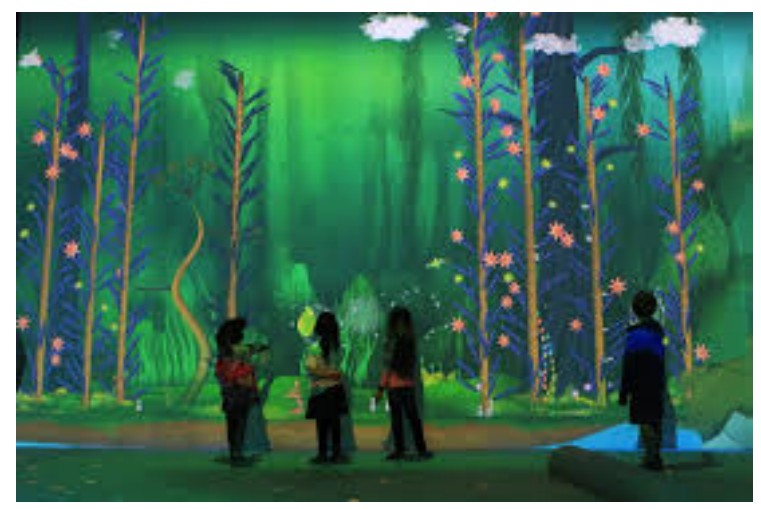

Connected Worlds exhibit - Used with permission of Stephen Uzzo

\section{Reflection starters}

- Given NSF's and the cyberlearning community's growing interest in leveraging data analytics for learning, how does the community address data privacy and other ethical concerns related to using participant data from tech-supported learning across multiple contexts/environments? What are the key concerns and challenges? How do OST contexts shape these conversations in a way that is different from those within the traditional school day?

- Considering NSF's focused interest in work at the human-technology frontier, how can approaches such as citizen science and making be used creatively to support development of the workforce of the future, especially in underserved populations?

- What new kinds of "ambitious mashups" of technologies and OST approaches can cyberlearning researchers conceptualize to broaden participation in STEM? How can we create experiences to inspire and support these innovative collaborations? 


\section{Recommendations from the Reflections Panel}

The panelists observed that the focus of Cyberlearning research on OST learning should not be on the setting or location or even the technologies that are used but on the kind of learning that is supported. In particular, these kinds of projects often examine learner agency and identity development in ways that can be informative in designing programs for a wide range of educational settings, which may include informal experiences that take place in schools as well as other places. Recommendations for future work in this area include:

- Design technology-supported hybrid in-school and OST experiences, building on what we have learned about authentic and interest-driven learning experienced in OST settings to create more engaging in-school STEM instruction that enables learners to have agency.

- Conceptualize citizen science projects and mobile exhibits/experiences more broadly as representations of community learning, in which learning is a collective and the community members help each other learn.

- Capitalize on this time of remote learning, when there is a blurring of where formal schooling ends and OST learning begins to design technological supports to blend the two more intentionally and productively to make formal learning more selfdetermined.

- Build on the affordances of digital games and play in general to motivate engagement and immersion in alternate realities to achieve learning goals.

- To address ethical issues related to concerns about collecting data through technologies used in OST settings, draw on the lessons of citizen science and involve learners in deciding what data should be collected and for what purposes, as well as in the analysis of those data.

\section{Project Examples and Resources}

For project examples, resources, and links, visit: https://circlcenter.org/resources/reflectionsreport/out-of-school-learning/. From this site, you will be able to review project abstracts, read related publications, and view videos produced by the projects. 


\title{
Theme 5: Trends at NSF and Beyond
}

\author{
Author: Sarita Pillai; Contributors: Jeremy Roschelle \& Judi Fusco
}

\section{Definition}

Cyberlearning projects have been conceptualized and implemented in the midst of a changing educational, policy, and funding landscape. A significant influence on this community has been the evolution of NSF's mid- and long-term research and investment priorities. In 2017, some of these priorities coalesced in the agency's 10 Big Ideas. Among the Big Ideas, three have already had notable influence in cyberlearning projects:

1. Harnessing the Data Revolution. Engaging NSF's research community in the pursuit of fundamental research in data science and engineering, the development of a cohesive, federated, national-scale approach to research data infrastructure, and the development of a 21st century data-capable workforce.

2. Convergence Research. Merging ideas, approaches, tools, and technologies from widely diverse fields of science and engineering to stimulate discovery and innovation.

3. Future of Work at the Human-Technology Frontier. Catalyzing interdisciplinary science and engineering research to understand and build the human-technology relationship; design new technologies to augment human performance; illuminate the emerging socio-technological landscape; and foster lifelong and pervasive learning with technology.

A fourth Big Idea, INCLUDES, forms alliances to transform education and career pathways to help broaden participation in science and engineering. And more recently, NSF 2026 which seeks community input into foundational research areas of the future that are boundarycrossing and out of the programmatic 'box' and that require long-term commitment at a significant scale.

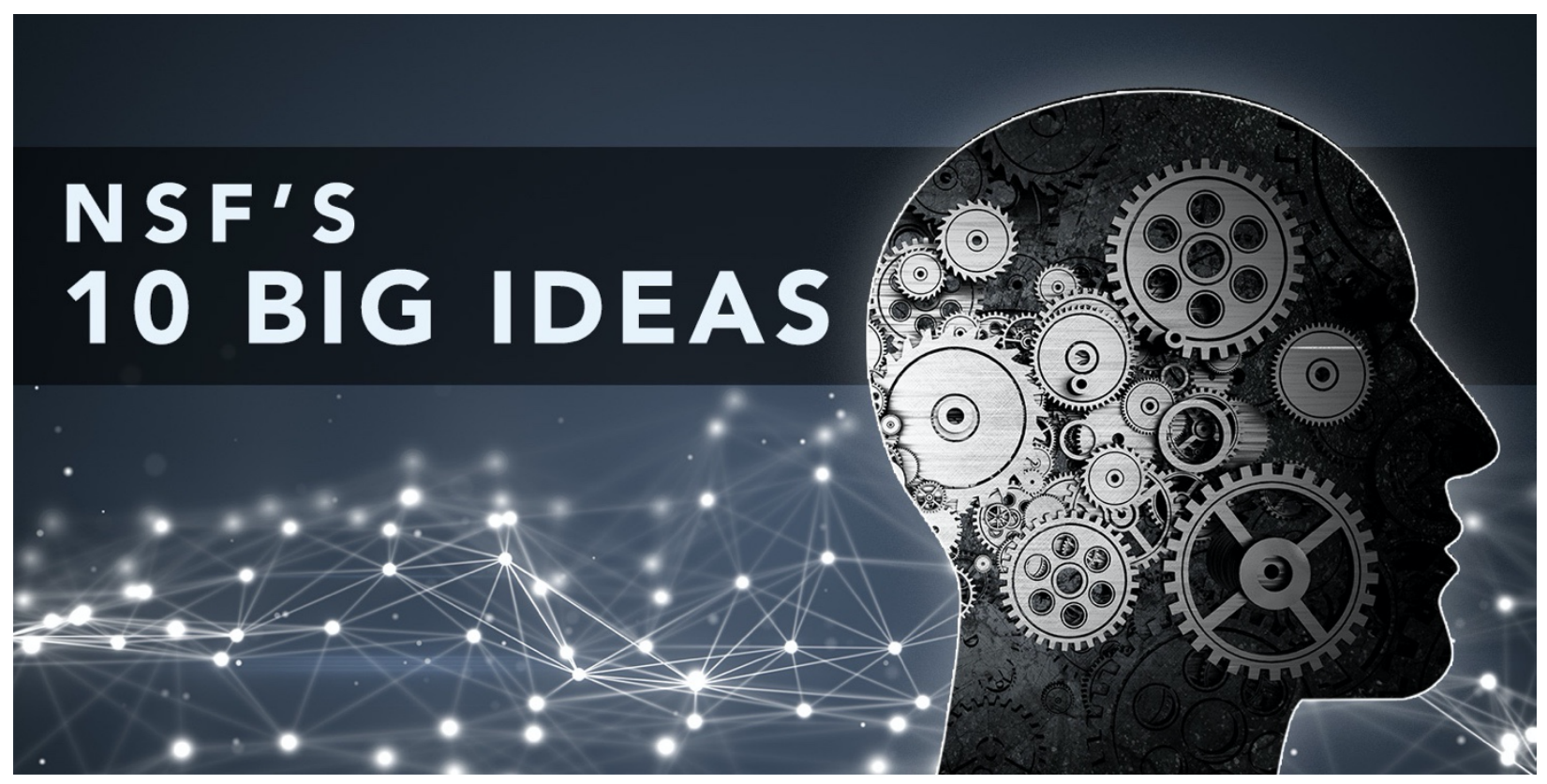




\section{Change over Time}

In reviewing the portfolio, we noted four significant trends/themes have a policy resonance. Some map to the aforementioned 10 Big Ideas; others have other resonances to other initiatives at NSF or beyond.

A first theme, Data Science Learning, teaches learners the tools, techniques, and habits of mind involved in experimentation, data collection, and analysis-and relates to the Harnessing Big Data idea. In the era of Big Data and a world increasingly awash in massive data sets, greater attention is being paid to the importance of building the foundational data science skills starting in K-12 education. The Data Science Learning theme was present in very early cyberlearning community activities, and one important platform, CODAP, was funded by an early grant. CODAP is a platform designed explicitly for data science education, allowing students to dynamically explore relationships, build visual representations, and to create and modify hierarchical structures, an important part of experiencing the doing of data science. CIRCL convenings provided opportunities for community organizing around the theme, although eventually, gatherings took on their own life outside of official cyberlearning events. The community has also discussed important issues related to the goals of data science education, the use of big data in educational research, theory-informed use of big data, the relationship between big data and convergence research, the barriers to integrating data science into education, and the pervasive issue of data ethics and privacy.

A second theme, Neuroscience, has been a focus of interest in the community and convenings have featured keynotes, expertise exchanges, and other professional activities on the topic. In 2013, the Obama administration launched a multi-agency Brain Initiative (and it continues today). Education researchers and neuroscientists are studying how neuroscience can influence learning, teaching, and the design of learning environments, and, in turn, how learning and teaching practices can inform neuroscience models. Although neuroscience is not one of the 10 Big Ideas, the convergence of cyberlearning, educational research, and neuroscience began early in the life of the cyberlearning program, with researchers exploring ways in which advances in technology can bridge the learning sciences and neuroscience in impactful ways. Despite a level of 'experimental skepticism' on the part of both technologists and neuroscientists, projects on multimodal models of learning, embodied learning experiences, virtual reality, and gaming have explored how neurocognitive tools such as fMRI, eye tracking, EEG, and fNIRS can be used to advance cyberlearning research and development. Increasingly there is interest in the needs of neurodiverse learners and those who learn 'differently' from the majority such as in the SAIL project. Several cyberlearning projects have focused on the application of neuroscience to inform interventions that target specific populations of students but many experts in the community posit that designing for diversity benefits all learners.

About halfway through the life of $C I R C L$, one of our program officers became involved in the NSF Smart and Connected Communities program and asked CIRCL to host an IdeasLab on the topic. The third theme, Smart and Connected Communities, utilize networks and technology to foster lifelong learning and problem solving in formal and informal settings, neighborhood communities, smart cities, across countries and the world. The IdeasLab was successful and led to several new collaborations among Pls. Cyberlearning published about "Smart and Connected Communities" and hosted further events at convenings over time. The Partnerships for Urban STEM Learning Hubs brought together educators, researchers, 
technologists, and students across multiple organizations within a city to develop and test a community learning hub design to support skill, literacy, and agency development for underserved youth. Complex issues remain to be grappled with, such as unanticipated conditions and changes that cause ripple effects across an interconnected system, establishing trusting relationships between partner entities and learning participants, issues of equity and access particularly in urban or rural locations, and data privacy concerns. Nonetheless, this hasn't been a recurrent theme of many projects. This could be because issues of learning are not highly featured in mainstream Smart and Connected Communities projects-and because cyberlearning projects that explore related issues - like involving students in mapping their communities have an adequate theoretical language without "smart and connected."

The Future of Work theme emerged last among these and has gathered momentum in directly funded projects. The field has envisioned a new machine age where humans will shape technology, where technology will shape human interaction, and where technologies and humans will collaborate in new ways to discover and innovate. Society's response to the COVID-19 pandemic is pushing us more rapidly; the future of work is likely to look much different than was conceived of even three months ago as more and more organizations facilitate learning in order to continuously transform themselves. While there has been limited attention to learning in the context of work within the cyberlearning community in the past, recent projects have begun to explore how new forms of work that engage teams with technologies can also provide stronger opportunities to learn and grow. There clearly remains work to be done to help more current and potential Pls understand what important, exciting projects "at the frontier" of work can look like and the role cyberlearning plays in transforming future workplaces into learning organizations.

The INCLUDES initiative has been highly relevant to cyberlearning which is inherently about design to support all learners. Many current INCLUDES projects are "pilots" that organize a group of stakeholders to tackle a challenge in educational and career pathways and few have a learning technology emphasis.

With NSF 2026 and the related Mid-Scale Research Infrastructure program, there is an opportunity for the cyberlearning community to think about its role in the future of learning and knowledge building. There remains a missing infrastructure component to the cyberlearning program that, if it was to be put into place, could enable outcomes to be more readily scaled. While the earliest version of the program attempted a tiered development category approach with an eye towards scaling impact, it never quite achieved that potential.

\section{Reflection Starters}

The CIRCL team has facilitated the presence of themes in the cyberlearning community that come from NSF policy or from external trends, and that have the possibility to resonate in this community's research. We see from the above cases that these themes take different trajectories: some germinate and then come to fruition elsewhere; others grow slowly; others gather some but perhaps limited momentum.

- How should we think about how thematic research (like cyberlearning) should relate to broader initiatives (like Big Ideas)?

- What can we learn from how such intersections have played out already? While connecting to broader initiatives involves considerable work, can we begin to 
formulate case scenarios and guidelines for choosing and engaging with broader initiatives?

\section{Recommendations from the Reflections Panel}

The panel reviewed the past intersections and recognized the value in each of them -- but also that the rationale for pursuing these particular intersections should be continuously reevaluated as policy leadership and policy priorities shift. Overall, the panel focused on three questions:

1. What does it mean to "scale up" in cyberlearning?

2. What mid-scale infrastructure would most benefit this community?

3. Where does the amassed knowledge within the cyberlearning community go next?

The panelists recognized that funding streams already exist at NSF and elsewhere for the typical sense of "scaling up." In this typical sense, a team might take results from an early exploration of an ambitious mashup under cyberlearning and seek funds elsewhere to more fully develop a program or product. A different sense of scale up is the ability to scale up this community's explorations of a particular design challenge; such that multiple teams and expertise might contribute to more rapidly and deeply advancing an exploration. One panelist wondered what it would be like if multiple projects could work together on aspects of "how do families engage in future learning with advanced technology?" or "how trajectories of learning data science could be supported across the lifespan." This led to the consideration of two intersectional ideas which, to date, have not been mined by the cyberlearning community in depth.

- Panelists recommended more intensive consideration of mid-scale infrastructures, which could be platforms, data sets, or instrumentation that enable multiple research projects to more rapidly conduct related cyberlearning explorations. The CIRCL team noted, for example, that one recurrent issue is that efforts to explore natural language interfaces in cyberlearning frequently bring up the need for the community to develop a more relevant corpus of social learning speech on a common platform -- a problem that is bigger than any one project. Instrumentation for multimodal analytics is another very challenging mid-scale problem that frequently arises in cyberlearning projects. A toolkit or platform to support ethical and equitable Al in learning research is also "infrastructural" in the sense of supporting many projects.

- Panelists also recommended a focus on knowledge management -- impacts of cyberlearning explorations would be greater if insights more readily accumulated in sharable forms. Panelists noted that experts in information or library science could be untapped allies. Further, reviewing the kind of interdisciplinary "convergence" that have proven useful in other novel research communities might shed new light on how the cyberlearning community could work more effectively together.

\section{Project Examples and Resources}

For project examples, resources, and links, visit: https://circlcenter.org/resources/reflectionsreport/emerging-trends/. From this site, you will be able to review project abstracts, read related publications, and view videos produced by the projects. 


\section{Conclusion: Recommendations for the Future}

As the reflections meeting came to a close, CIRCL asked panelists to reflect on the past, present, and future of cyberlearning. We received a dozen written reflections and also reviewed the recorded discussion. In so doing, several important recommendations arose and are presented below.

\section{Communicating Unique Characteristics of the Field}

As we observed earlier (see "History of Cyberlearning"), the community and its collection of research projects have taken shape gradually over about a decade. Although there is more of a sense of community now than when cyberlearning funding began, many participants, newcomers and community members are not yet clear about what makes this work distinctive: what's the difference between "digital learning" and ideas investigated in this smaller, more focused field?

Digital learning is an expansive field of entrepreneurial, policy, and research interest. Generally speaking, much of the effort goes into figure out today's digital resources can be applied effectively in the pursuit of learning. Research produces the knowledge to improve designs, support high quality implementations, and study efficacy. This research is important work and many NSF, U.S. Department of Education, philanthropic, and other sources of funding provide support for it.

Cyberlearning research is born of a different problem-not how to apply today's technologies, but getting ready for the learning technologies that will become prominent in the future. Underlying technologies and platforms are changing rapidly -- and yet researchbased knowledge grows very slowly. Tomorrow's platforms are likely to be very different from those today, and so today's knowledge may not readily extrapolate to new possibilities. Therefore, to be ready with research-based knowledge when the future arrives, the research about future learning needs to begin now. Cyberlearning most importantly has a focus on emerging technologies that are likely to become prominent 5-10 years from now.

Following from this need, panelists celebrated a set of key characteristics of the field:

- Exploratory. Panelists strongly supported a focus on exploratory projects because we cannot definitively know what form the future will take, and thus we need to harness the imaginations of the designers.

- Ambitious Mashups. Panelists strongly resonated with this concept (discussed earlier), which emphasizes explorations of unique combinations of emerging technologies. Explorations of mashups opens our eyes to divergent future possibilities.

- Research and Design Iterations. Panelists valued cyberlearning as a field that iterates rigorously between design and research. The field builds prototypes in order to conduct research with them, and thereby to understand the theories, methods, and design patterns that will be important in the future.

- Interdisciplinarity and Convergence. Panelists noted growth of practices that integrate multiple expertises, recommending that core teams include both computer science and learning sciences expertise. Of course, these two disciplines are just a beginning for many successful cyberlearning projects; other necessary disciplines need to engage and work convergently to answer shared research questions. 
- Lifelong and Lifewide Learning. Many other research programs occur in silos according to the age, grade-level or special needs of the learner or are organized by the topic that students will learn. The field of cyberlearning projects notably traverses these boundaries. Multigenerational learning is explored. Researchers who worked with early learners, school-aged learners, university-aged learners and beyond exchange ideas. Boundaries between formal and informal learning are crossed. This is important.

Going forward, panelists raised provocative remarks about where the field could further articulate its self-understanding and better argue for funding resources:

1. What is the right type of shared infrastructure (what NSF terms "mid-level infrastructure") that is needed to advance an exploratory community of researchers?

2. How can the field better argue for its research-and-design activities as rigorous and capable of producing distinctive and much-needed outputs?

3. How can the field better investigate "constellations" of technologies used over a variety of contexts in a person's lifetime and not only designs for particular learning experiences?

4. How can the field sharpen its disciplined balance between unpacking the exciting possibilities of emerging technology and discovering how people learn equitably?

\section{Strengthening Reporting of Project Outcomes}

In the collection of projects we reviewed, clear examples were found of projects that pioneer ambitious mashups. Examples also develop important strands of learning theory, refine research methods, or bring valued new perspectives to addressing equity. While there is a sense of excitement and progress, panelists lamented that overall it is too hard to locate the insights and outcomes of cyberlearning projects. It is easier to find information on what will be explored than on what was learned through the exploration.

Perspectives from panelists on this challenge overlapped around the following themes:

- Clarity on Outputs. Broadly speaking, project outcomes include research findings and design insights, and include both "intellectual merit" and "broader impacts." Yet there is a sense that the field is clearer about what kinds of things it explores than it is about what it produces. Funders, of course, want to know what outputs the funding leads to, so this is a critical issue for sustaining funding to the field.

- Innovative Communication Formats. Panelists appreciated the efforts of CIRCL to advance novel dissemination formats, like primers, synthesis, and perspectives. Finding the right formats for documenting knowledge so it is "useful, intelligible, and relevant" to audiences is critical. Existing conferences and journals can be helpful, but novel venues and formats are judged by panelists to be very important.

- Audiences. Panelists highlighted the broad audiences that care about and have much to learn from this field. One panelist suggested that shaping the public image of what learning looks like is very important. Others focused on audiences such as educational practitioners, industry and entrepreneurs, and policy-makers.

- Themes. Panelists cautioned against assuming that themes like the previous NSF "Big Ideas" would continue into the future. They recognized that connecting to broader societal themes accelerate communication. For example, cyberlearning informs us 
greatly about remote and online learning, which relates to the current pandemic. Also, themes of human-centered computing and social justice with Artificial Intelligence are on the rise. The field could re-think what broader societal themes best amplify its messages.

Overall, CIRCL staff resonated with a recommendation to support the field in thinking about knowledge management, so that more outcomes and outputs of this research can be more readily available to multiple audiences.

\section{Enhancing the Equity Work}

Expert panelists advocated for maintaining a strong focus in cyberlearning projects on equity, including anti-racism and social justice. To the CIRCL team, equity has been a persistent and important feature of many projects. And yet, the equity-relevant characteristics of projects can seem diffuse. The field needs to more clearly define what its equity work in this field and how it expects to make progress. Further, stronger reporting of equity relevant outcomes is needed, whether those outcomes are design innovations, research findings, or new forms of participation in the process of investigating future learning.

Panelists suggested a range of possible actions for the field in the future. These include:

- Involving diverse participants in the work. Cyberlearning projects already have a strong history of women leaders as well as some history of leaders who a Black, Latinx, and other identities. Panelists suggested renewing efforts to cross-connect to HMCUs and MSIs. Structurally, cyberlearning projects should be designed to include institutions and leaders who are not already privileged in their search for research funding.

- Tackling pressing issues. Ethical issues regarding artificial intelligence and data analysis are worrisome to the field and to panelists; it is important to accelerate the field's progress on these issues.

- Human-centered computing is another broad theme that implies participation of stakeholders in the world, and cyberlearning could lead by providing models of what it looks like to work on these issues together.

- Openness in knowledge exchanges. Panelists also noted how sharing knowledge broadly is essential to creating an inclusive shared community that can collaborate on equity issues together. 


\section{Appendix 1: Findings from the 2020 Project Exit Survey}

We reviewed projects for their outcomes, which included reviewing answers to an exit survey question that asked projects to identify their contributions to each of computing and learning sciences. Based on this, we identified three classes of contributions that projects are making. We do not intend these to be levels nor categorizations of projects: all the classes of contribution are valuable and many projects pursue multiple classes of contribution simultaneously. We do think this simple framework may be useful in asking projects to report their outcomes in the future, so the contributions can be more readily captured and understood. We propose three classes of contribution:

1. Advance. Projects often seek to use a particularly challenging situation or environment in learning with technology to drive a fundamental advance in their respective fields. In computing sciences, these come up often in collaborative learning situations-where sensing, detecting or recognizing learning-relevant features of human interaction is quite challenging and new techniques must be developed. In learning sciences, these often advance cutting edge theory on a concept such as embodied cognition, collaborative learning, or assessment-the technology-rich environment can be particularly fertile for advancing these areas of theory.

2. Articulate. As previously mentioned, many projects explore the potential of a novel configuration of technologies and other learning resources, e.g., an ambitious mashup. The outcomes of such an exploration are often a better understanding of how two or more different promising approaches could interconnect, combine, or relate in service of learning-and how they can interoperate computationally.

3. Advise. Projects also often develop guidelines, design principles, cases, exemplars, and other forms of documentation that can support a broader field to utilize what's known. Advising can also involve identifying problems that deserve more attention by the field of researchers, which can lead to a later Advance.

\begin{tabular}{|c|c|c|}
\hline & Computing Sciences & Learning Sciences \\
\hline $\begin{array}{l}\text { Advance } \\
\text { The project advances the } \\
\text { foundations of the field } \\
\text { by studying problem in } \\
\text { learning }\end{array}$ & \begin{tabular}{|l} 
Examples: \\
- $\quad$ Detecting speech moves \\
in naturally occurring \\
collaborative discourse \\
- \\
Recognizing gestures as \\
learners work with \\
scientific models \\
- Automatically sensing \\
"rapport" among learners
\end{tabular} & 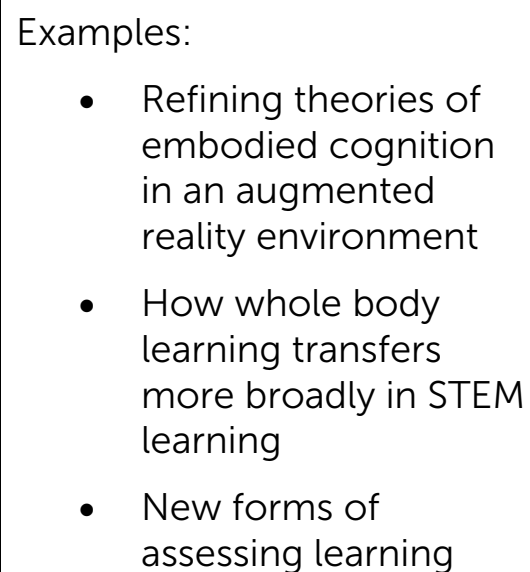 \\
\hline
\end{tabular}




\begin{tabular}{|c|c|c|}
\hline $\begin{array}{l}\text { Articulate } \\
\text { The project investigates a } \\
\text { novel application or } \\
\text { mashup of emerging } \\
\text { advances in one or more } \\
\text { fields, seeking to } \\
\text { understand how to } \\
\text { improve how support for } \\
\text { learning }\end{array}$ & $\begin{array}{l}\text { Examples: } \\
\text { - How data analysis } \\
\text { techniques can be } \\
\text { embedded in game-like } \\
\text { learning environments } \\
\text { - How agent-based and } \\
\text { system-dynamic models } \\
\text { can fit together in a } \\
\text { learning environment }\end{array}$ & $\begin{array}{l}\text { Examples: } \\
\text { - Articulating how } \\
\text { critical theories and } \\
\text { learning sciences } \\
\text { theories relate } \\
\text { - Understanding } \\
\text { whether haptics } \\
\text { support young } \\
\text { learner's embodied } \\
\text { cognition }\end{array}$ \\
\hline $\begin{array}{l}\text { Advise } \\
\text { The project consolidates } \\
\text { a range of insights that } \\
\text { could be more broadly } \\
\text { applied }\end{array}$ & $\begin{array}{l}\text { Examples: } \\
\text { - Recommendations on } \\
\text { CS techniques for } \\
\text { implementing universal } \\
\text { design for learning } \\
\text { - How learning analytics } \\
\text { could relate to } \\
\text { assessment of } \\
\text { competencies }\end{array}$ & $\begin{array}{l}\text { Examples: } \\
\text { - Guidelines for } \\
\text { pedagogy that is both } \\
\text { inclusive and } \\
\text { innovative } \\
\text { - How advances in } \\
\text { learning technologies } \\
\text { could be applied in } \\
\text { new settings, such as } \\
\text { liberal arts colleges }\end{array}$ \\
\hline
\end{tabular}

In reviewing many projects, our exit survey also identified several common drivers of innovation. These are contexts that occur in multiple cyberlearning projects and appear to be particularly fruitful for pursuing advances in cyberlearning that can span advances, articulations and advice classes of contribution. Some key drivers are listed below and further elaborated in our theme areas that follow. Our further theme areas also consider the portfolio more broadly than the exit survey (and thus is more inclusive than this list).

- Understanding Collaborative Learning and Embodied Learning (beyond individual minds to include social learners and whole body learning)

- Improving Assessment of Learning (beyond what is already measured well, for example, to new competencies)

- Multimodal Teaching and Learning (beyond multiple representations to multiple forms of participation)

- Learning Outside School or in Novel Space (beyond formal school structures and routines)

- Advancing Capabilities of Artificial Intelligence (beyond tutoring or making recommendations) 


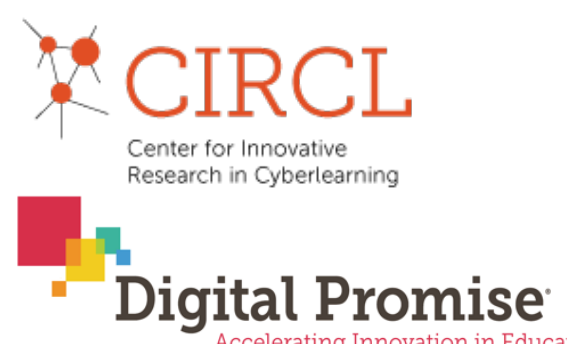

Accelerating Innovation in Education

\section{SRI Education}

NARC

at the UNIVERSITY of CHICAGO

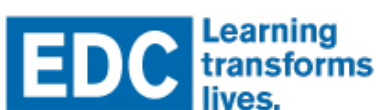

